\title{
AN INTEGRATED STUDY OF THE GRAYBURG/SAN ANDRES RESERVOIR, FOSTER AND SOUTH COWDEN FIELDS, ECTOR COUNTY, TEXAS
}

Annual Report

August 1, 1997 - July 31, 1998

RECEIV:

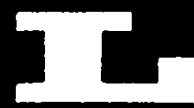

By

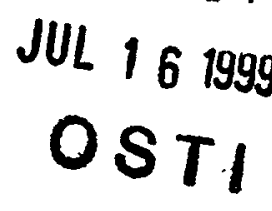

Robert C. Trentham, DGS

William C. Robinson, M.S.

Kevin Widner

Richard Weinbrandt, Ph.D., P.E.

Date Published: June 1999

Work Performed Under Contract No. DE-FC22-94BC14982

Laguna Petroleum Corporation

Midland, Texas

\section{National Petroleum Technology Office \\ U. S. DEPARTMENT OF ENERGY \\ Tulsa, Oklahoma}




\section{DISCLAIMER}

This report was prepared as an account of work sponsored by an agency of the United States Government. Neither the United States Government nor any agency thereof, nor any of their employees, makes any warranty, expressed or implied, or assumes any legal liability or responsibility for the accuracy, completeness, or usefulness of any information, apparatus, product, or process disclosed, or represents that its use would not infringe privately owned rights. Reference herein to any specific commercial product, process, or senvice by trade name, trademark, manufacturer, or otherwise does not necessarily constitute or imply its endorsement, recommendation, or favoring by the United States Government or any agency thereof. The views and opinions of authors expressed herein do not necessarily state or reflect those of the United States Government.

This report has been reproduced directly from the best available copy. 


\section{DISCLAIMER}

Portions of this document may be illegible in electronic image products. Images are produced from the best available original document. 
$\mathrm{DOE} / \mathrm{BC} / 14982-16$

Distribution Category UC-122

An Integrated Study of the Grayburg/San Andres Reservoir, Foster and South Cowden Fields, Ector County, Texas

\author{
By \\ Robert C. Trentham, DGS \\ William C. Robinson, M.S. \\ Kevin Widner \\ Richard Weinbrandt, Ph.D., P.E.
}

June 1999

Work Performed Under Contract DE-FC22-94BC14982

Prepared for

U.S. Department of Energy

Assistant Secretary for Fossil Energy

Daniel Ferguson, Project Manager

National Petroleum Technology Office

P.O. Box 3628

Tulsa, OK 74101

Prepared by

Laguna Petroleum Corporation

P.O. Box 2758 .

Midland, TX 79702-2758 



\section{TABLE OF CONTENTS}

EXECUTIVE SUMMARY V

ABSTRACT v v

INTRODUCTION

GEOPHYSICS 3

Inversion Modeling $\quad 4$

$\begin{array}{ll}\text { Methodology } & 6\end{array}$

$\begin{array}{ll}\text { Seismic-Derived Porosity Maps } & 8\end{array}$

GEOLOGY 9

Water Analyses 9

Source of Produced Water $\quad 12$

Successful Isolation With CIBP 12

$\begin{array}{ll}\text { Unsuccessful Isolation With CIBP } & 13\end{array}$

Successful "Pipeline" Frac 13

$\begin{array}{ll}\text { Successful Multi-Zone Completion } & 14\end{array}$

Sudden Change in Production 14

$\begin{array}{ll}\text { Coned Water } & 15\end{array}$

Brock Lease Water Analyses $\quad 15$

Foster-Pegues Water Analyses $\quad 16$

ENGINEERING 16

$\begin{array}{ll}\text { Production for } 1997 & 16\end{array}$

$\begin{array}{ll}\text { Simulation Results } & 16\end{array}$

$\begin{array}{ll}\text { Field Engineering Objectives } & 17\end{array}$ 
Re-Alignment of Upper Grayburg Flood

Bottom Hole Pressure Testing

Recommendations

Brock Lease

Foster-Pegues Lease

H.C. Foster Lease

21

Witcher Lease

RESULTS

22

TECH TRANSFER EVENTS

ACKNOWLEDGEMENTS

FIGURES

$25-49$ 


\title{
EXECUTIVE SUMMARY
}

For a part of the Foster and South Cowden (Grayburg-San Andres) oil fields, the production of $125,000 \mathrm{BO}$ incremental has been accomplished through a careful evaluation of potential workover candidates, the use of modern fracturing technology and 3D inversion modeling, coupled with reservoir simulation. The 3D seismic survey acquired in conjunction with this DOE project has been used to calculate a 3D inversion model, which was then used to provide detailed maps of porosity within the productive upper Grayburg Formation. Geologic data, particularly from logs and cores, have been combined with the geophysical interpretation and production history information to develop a model of the reservoir that defines estimations of the remaining producible oil. The results of testing in the new drills and workovers led to the decision to concentrate on the upper Grayburg waterflood. This in turn led to the abandonment of the nonfloodable lower Grayburg and San Andres reservoirs. Buildup tests have been used to determine that the majority of upper Grayburg producers require restimulation to optimize the flood. A series of re-stimulations have resulted in a seven (7) fold increase in production from the refraced wells. Produced water analyses are now being utilized to complement the engineering data set.

\begin{abstract}
A project to recover economic amounts of oil from a very mature oil field is being conducted by Laguna Petroleum Corporation of Midland, Texas, with partial funding from a U.S. Department of Energy grant to study shallow carbonate rock reservoirs. The objectives of the project are to use modern engineering methods to optimize oil field management and to use geological and geophysical data to recover untapped potential within the petroleum reservoirs. The integration of data and techniques from these disciplines has yielded results greater than those achievable without their cooperation. The cost of successfully accomplishing these goals is to be low enough for even small independent operators to afford. This article is a report describing accomplishments for the fiscal year 1997-1998.
\end{abstract}

The realignment of the waterflood and all additional well work awaited the completion of the seismic based, geologically guided, history match and engineering simulation. A seismic derived, geology guided porosity map, with the same data density as the simulation, was constructed. A "cook book" method for deriving seismic porosity maps from an inversion modeled $3 D$ volume has also been developed. A no-flow (low porosity) boundary trending SW to NE across the study area was identified. The discovery of this, boundary necessitated the rotation of the simulation model. The results of the new history match and simulation have significantly changed the focus of the project. The San Andres and lower Grayburg are being abandoned (for the near future) in a number of wells as they are not considered to be economic waterflood targets.

After the decision was made to concentrate on the upper Grayburg as a flood target, build-up tests were run on each well, produced waters samples collected, 
and Cast Iron Bridge Plugs (CIBP's) set. A series of pressure buildup tests were run to determine the status of the reservoirs. Water samples were taken to characterize the produced waters and complement the engineering data set. CIBP's were set in these wells where the San Andres and lower Grayburg were not significantly contributing to production. Build-up tests were rerun, and water samples collected, to determine the future course of action. As a result of the build-up tests, it has been determined that the majority of producing wells require large refracs to optimize the waterflood. A program of recompletions is now in progress.

Produced water chemistry has slowly evolved into valuable tool to complement traditional engineering testing as a means of understanding the reservoir. A table of "Virgin" water chemistries for the upper and lower Grayburg and San Andres, and the various injection system makeup waters has been developed. The injection waters have included Ogalalla, Santa Rosa, Hendricks Reef, Canyon and Ellenburger. Water analyses have been used to assist in evaluating: the success or failure of setting CIBP's above the lower Grayburg, of pipeline and traditional fracture simulations, the cause of sudden drops in production, and the potential for coning water from a deeper horizon.

The new wells and workovers have resulted in $125,000 \mathrm{BO}$, incremental, being produced to date. This production is incremental added reserves that would not have been produced without the work done as a result of this study. The realignment of the water flood and additional well work is anticipated to add significant additional reserves. 


\section{Introduction}

The objective of this two-phase study is to demonstrate an integrated methodology for reservoir characterization of a shallow shelf carbonate reservoir that is both feasible and cost effective for the independent operator. Furthermore, it will provide one of the first public demonstrations of the enhancement of reservoir characterization using high-resolution three dimensional (3D) seismic data.

This particular project is evaluating the Grayburg and San Andres reservoirs in the Foster and South Cowden Fields, Ector County, Texas (Fig. A). This sixty eight (68) year old field was approaching its economic limit and the leases evaluated would have been abandoned in ten (10) years. A multi-disciplinary approach to waterflood design and implementation, along with the addition of reserves by selective infill drilling and deepening, is being applied to this field. This approach in reservoir development will be applicable to a wide range of shallow shelf carbonate reservoirs throughout the United States.

The first phase of the project included the design, acquisition, and interpretation of the 3D seismic survey, the collection and evaluation of geologic (core and log) data, and engineering (historical production, well test, injection) data from a variety of sources. From this work, a geologically based production history model was simulated. Based on the recommendations made at the end of Phase I, three new wells were drilled, one existing well was deepened, two wells were worked over, one TA'd well was re-entered, and one well was converted to injection. In addition, the quality of the injection water was greatly improved, a necessary step, prior to increasing injection in the project area. The analyses of the seismic data have become a major factor in defining productive properties of the Grayburg reservoir. Seismic inversion is used to convert the seismic data to velocity traces, a form from which a quantitative evaluation of reservoir properties is extracted. Calibration of seismic-derived interval velocity attributes, using well log porosity information, enable mapping the distribution of porosity of the individual upper Grayburg zones comparable to production fluid flow zones. These detailed maps have modified the earlier reservoir description made from sparse subsurface data. This revised picture discloses reservoir compartments not recognized before, serves as a vital parameter in the revised engineering model of the reservoir, and modifies the influence of the production history and the original oil in place values. Future drilling will be guided by the new engineering model.

Initial seismic analyses targeted an understanding of the correlation of basic geology and reservoir factors to seismic wiggle-trace data. Stratigraphy specific to a thick carbonate sequence with few internal seismic reflectors was examined, including a hands-on review of core to establish seismic-to-rock relationships. Consideration of the effect of rock properties, particularly porosity, on seismic data response, focused on those most important factors for continued study. 
Forward modeling was employed to visualize aspects of the geology with seismic reflection response, to exactly identify key geologic levels in the seismic data. Observations were made of the various seismic waveform attributes, but no strong correlations with important rock properties have been recognized. The studies of the seismic data, including inversion modeling, have been done entirely using inexpensive, but effective, PC-based seismic interpretation software well suited to analyzing 3D seismic data.

Melding new core and log data (products of Phase I recommendations) with preexisting data led to the development of a better understanding of the depositional and diagenetic history of the Grayburg and San Andres Formations.

Geologic log markers within the Grayburg represent low permeability zones that act as vertical barriers to fluid movement during oil production. Areas of reservoir with low porosity dolomite or anhydrite-filled dolomite result in poor production qualities. and reduced water injection capacity. Also, core and log evaluation associate the top of the San Andres with a major karst event, and provide insight for a methodology to identify potential water producing intervals. Thus, the San Andres has been downgraded as a potential waterflood target.

The initial simulation model results, using seismic-derived porosity maps, fit within expectations, although some porosity modifications were made. Continued well testing has provided data necessary for a more complete simulation. Team members worked closely to develop methodologies to bridge the distances among historically diverse scientific disciplines.

The accomplishments of the previous reporting periods are a foundation for the current results discussed in this report, and the continued monitoring of the effects of that work is part of the goals of the current Phase. During the Phase I period, field management was influenced by preliminary geological work done to define the distribution of porosity within the upper and lower parts of the Grayburg Formation and within the upper part of the San Andres formation.

Implementation of the field development recommendations made at the end of Phase I were based on an engineering simulation run using production history and geologic models. Oil production was doubled as a result of that work. Several wells were worked over and newly drilled wells contributed additional high quality subsurface core and log data. A "pipeline" fracturing technique, designed to double the induced fracture length over other methods, was used to improve fluid production by more effectively contacting the reservoir. Significant to the waterflood project was the improvement of injection water quality by system redesign. Monitoring the effect of using improved injection water continues. Water chemistry analyses, noting the difference of salinity of Grayburg fluids versus San Andres fluids, have been used to determine the reservoir origin of produced water, implicating San Andres water contamination of Grayburg production. Development of a produced and injected water chemistry database also continues. 


\section{GEOPHYSICS}

This project is about integrating geology, engineering, production history, and geophysics to build the most complete understanding possible of a mature oil field, for future development decisions. The subject of the geophysical report is seismic Inversion Modeling and its use in mapping rock properties in the Grayburg carbonate reservoir. This report references the previous annual report and distills many of the findings therein described.

Discovered in the late 1930 's, the field has had several operators, and a long waterflood history. The 3D seismic survey acquired is 3.3 square miles, intended to image the Grayburg reservoir at 4,000 feet. One requirement for the DOE is to develop a methodology for other workers to use regarding multiple scientific disciplines, and this report details the geophysical work done in a "cookbook form". Another DOE objective is to give independent operators the ability to apply these methods using inexpensive computers and software. The Inversion Modeling process was accomplished within these criteria at the offices of Laguna Petroleum.

Maps have been made using analyses of seismic Inversion Model data (calibrated to well data) to show the distribution of gross average rock porosity of several oil productive zones of the upper Grayburg formation beneath the 3D shoot. These data were factored into an engineering model to define reservoir capacity and preferred fluid flow, explaining the historical production of oil and water and the injection of fluids. This overall model has guided decisions for future expenditures for workovers, recompletions, and new wells. Figure 1 compares a map of the seismic-derived porosity distribution with a map made using only log-derived porosity data, and demonstrates that increased data density offers a more complete image of porosity distribution.

The overall task defined for the geologist and geophysicist is to define geologic parameters significant to the production and determine ways to map those parameters. When the engineer is initially involved with those decisions, his needs and concerns can be addressed as part of that task. Primary among his needs are production zone-dependent reservoir characteristics at the scale of the reservoir, specifically, the flow unit scale. Quantitative, not relative values are required to be useful for production history comparison. Reservoir porosity is the factor with the most influence on production and waterflood injection; permeability is proportionally related to productive porosity in this project area.

A seismic interpretation of the Grayburg is simplified since that sequence contains no seismically discreet siliciclastic layers within the reservoir in this project area that would affect the seismic data. Changes in porosity will cause a seismic reflection response because porosity affects sonic velocity, thus, acoustic impedance. Thickness of producing zones is measured using log correlations of thin siliciclastic markers. The thickness maps are essential to 
calculate the same zones for the seismic data analysis. Porosity values are determined from log calculations. Structure is not a primary factor controlling production at the project scale, but may have profoundly affected facies distributions. The geophysical task is to isolate production zones in seismic time, convert the seismic data to a reservoir-quantitative form, and to produce maps of value to the engineer for detailing the distribution of oil in place.

The first consideration for the seismic analysis of any project is where to begin, since different projects have different geologic considerations. Tracking seismic reflectors and making time and reflection amplitude maps are a start, but do not define the critical factors of rock properties. Seismic waveform attributes are a button-click away, but analyses of results are vague and probably useless on the required scale, even when applied critically. The foundation of the project is to relate seismic data to well data through theory, as preferable to empirical or statistical methods. Results are then understandable and errors are noticeable. Inversion model results can be evaluated in context with rock properties, whereas waveforms (wiggles) are essentially in a foreign script, a convenience of data recording. Reflections are only a response to relative rock property changes. Why would a geophysicist be negative about reflections? Because reflections don't contain the quantitative answers, as will be shown.

\section{Inversion Modeling}

Seismic reflection data have no stratigraphic significance ... until geologic data are incorporated using well control and interpreter experience. Actually, a number of technical points (phase, for one) must be met to even qualify any seismic display. Inversion Modeling is a process that removes the ambiguities of the seismic wavelet to establish some uniqueness to the data model. The model then has some characteristics of the stratigraphy to which the seismic data are the response. In a nutshell (which will be cracked later) Inversion Modeling removes the wiggle and infuses geologic constraints into the seismic data set. A discussion of Inversion Modeling procedure follows in the methodology. Figure 2 shows profile L-L', an example of the seismic data in the project. The zone of most interest is only about 24 milliseconds of the upper Grayburg. Figure 3 is an enlargement of a part of the data in figure 2, showing the inversion Model traces.

Expectations from the seismic data will be considered from acquisition and processing parameters. The survey data quality embodies actual fold, noise, wavelet bandwidth and phase. The scale of the geology to be imaged is compared to the resolution of the seismic analysis. Inversion Modeling reveals the sensitivity of seismic traces to the qualities of wavelet and noise, and model traces may represent the true seismic resolution.

A number of expected intrinsic problems of defining rock properties are considered. Porosity values are measured from logs, but calibration varies with log type. The difficulty of normalizing porosity values causes inherent scatter in 
the porosity calibration data set. Reservoir anhydrite also complicates porosity measurements. Sonic velocity (both seismic and log-derived) responds to changes in primary porosity but is not very responsive to vuggy porosity. By comparison, the neutron-sourced log device measures total porosity. Lithology contrasts can potentially appear seismically the same as rock property changes. Synthetic seismogram models show that geologic correlations are not represented by reflections, so that placement of analysis zone boundaries in $x, y$, $t$ space contains some error. Waveform attributes will not define rock properties in thick carbonate reservoir situations; reflections do not quantify reservoir properties but only show relative changes.

Inversion Model building is an important tool of geophysics for quantifying rock properties. A brief description of the method is intended to reveal the requirements for model building and the "do-it-yourself" nature of modeling using the PC. The interpreter familiar with the geology will be best qualified to assess the model results. The software used for this project is Vest Exploration Services 3DINV program. It creates a model controlled by user constraints. The modeling is performed using a Generalized Linear Inversion (GLI) method that, by iteration, converges on a best result. This program internally creates a pseudo-sonic log trace from each seismic trace. Constraining the model refers to infusing into the model traces values of sonic velocity and horizon location; other constraints of known waveform characteristics of amplitude and frequency bandwidth are absent from the model traces. Phase of the input seismic data must be zero. The results of a model are greatly influenced by data quality. Seismic noise is the worst contaminator since it decreases the accuracy of seismic reflection placement and amplitude. Data processing methods involving wavelet shaping, specifically of frequency and phase, affect model trace accuracy and vertical resolution.

Model Analysis is the ultimate goal and produces the maps needed. Techniques used for the Grayburg are described in the step-by-step discussion that follows. The qualification of the model accuracy and resolution rely on the model analysis of geologic zones and relationships to subsurface knowledge.

The upper Grayburg zones appear to be well described in the final analysis. However, seismic relationships for lower Grayburg zones (source of some oil production) with subsurface data have not been strong enough to be of value. Similarly, work with the San Andres has been unfulfilling. The reservoir internal structure of these problem zones is more complicated and analysis zones are thinner. Lateral relationships in the karsted San Andres are complex compared to the upper Grayburg.

\section{Methodology}

The methodology is summarized relating seismic inversion modeling with production history modeling and geology: 


\section{Production History}

1. Past production was estimated and allocated to correlated zones of the upper Grayburg.

\section{Geological Preparation}

1. Geologic data were prepared in a data base format. Available logs were correlated, production zones were defined, and log correlation's were made for important zone boundaries (Figure 4).

2. Depth (Figure 5) and thickness (Figure 6) maps were made of the major production zones (typically $100^{\prime}-200^{\prime}$ thick). Zones were subdivided into zones as thin as about $50^{\prime}$ for further study.

3. Digitized neutron, density, and sonic log curves were used to calculate porosity and its relation to zone thickness. Average porosity, and other porosity parameters were calculated for the upper Grayburg zones. Gross average porosity is the parameter most likely sensed by the seismic tool.

4. Relationships of log properties were studied in core and logs. A very important revelation observed from core study is that lithology throughout the Grayburg is consistently dolomite and anhydrite, so that noncarbonate lithologies are unlikely to complicate the seismic analysis.

\section{Geophysical Procedure}

1. Basic, conventional seismic time maps were made for the Queen, lower Queen, Grayburg, San Andres, and Holt reflections. Waveform attributes associated with some of these reflections were observed.

2. Synthetic seismogram models (Figure $7 \& 8$ ) were made to examine seismic relationships to geologic data. The top of the Grayburg A zone geologic correlation is represented as a reflection in the west part of the 3D survey but not in the east part because of dolomite within the lower Queen. The other Grayburg zones do not have associated reflections at all since they are not bounded by significant non-carbonate clastic beds.

3. Sonic logs integrated in time were measured for interval time and thickness to determine average velocity of each zone. Figure 4 shows the sonic log with the velocity calculations, the synthetic seismogram and the Inversion Model traces at the well tie. The figure provides a comparison of the three data types, and a sense of the resolution of each. This velocity field from all sonic logged wells was mapped (contoured) and digitized for the area of the 3D survey. These contour maps were revised for final use by considering the distribution of velocity from inversion-derived maps. The final isochron maps were calculated using these velocity maps. 
3. Isochron maps were calculated from subsurface-mapped isopach and the interval velocity maps. In fact, a depth to time conversion was done. Time thicknesses were mapped for the Grayburg $A, B$, and $C$ zones.

4. An inversion model was calculated for the 3D volume. The input parameters for the model include reflection horizons, sonic velocities determined from logs, and frequency and amplitude characteristics of the seismic data. In common with the 3D survey, the model traces replace seismic wiggle traces. The model trace lengths (in time) are shorter than the seismic traces, since they are windowed from 500-1100 milliseconds around the zones of study.

6. Profile comparisons were made of the model traces with the sonic logs in time for qualification purposes. The inversion model traces have a minimum resolution of about 50 feet, compared to the sonic log with one foot resolution, or a wiggle trace of undefined resolution. Refer to Figure 3.

7. The lower Queen reflection horizon picks were edited on the Inversion Model traces to map the lithologic boundary of the top of the lower Queen clastics. This horizon is the reference for horizon building the Grayburg horizons. The lower Queen is a reasonable lithologic boundary near the top of the Grayburg.

8. Isochron maps were successively added, beginning with the lower Queen reference, to build horizons for the A, B, and C. Deeper horizon levels were also calculated for the Grayburg, as well as the San Andres. For example, the isochron of the lower Queen to Grayburg A interval, added to the lower Queen time horizon, yields a time horizon for the Grayburg A.

9. Average Interval Velocity was calculated from the Inversion Model for the Grayburg A and B zones, using the zone boundary horizons and the interval averaging routine in the Vest seismic software. These maps represent the seismic response to dolomite velocity at specific places in the rock sequence.

10. The values of Average Interval Velocity were graphically compared to well log-derived values of Gross Average Porosity at well locations. The zones analyzed in the Inversion Model lie between the calculated time horizons. Figure 9 shows the cross-plot relationship of gross average porosity with seismic-derived velocity for the Grayburg A zone (thick line). A Schlumberger chart (curved dashed lines) shows the commonly used relationship of sonic log velocity and measured porosity. That chart has been used as a guide to judge the normalized values of velocity from the Inversion Model and to interpret the slope of the line used to convert the velocity data to porosity data. 
11. A linear function was determined from the cross-plotted points, and was used to convert the Inversion Model velocity values to Gross Average Porosity values using the Vest software. The map of calibrated Gross Average Porosity of each Grayburg zone was used in the production history model.

12. Quality of the seismic-derived porosity map was partly assessed by the scatter within the alignment of cross-plot points. By comparison, that scatter is comparable to the scatter of laboratory-derived relationships of velocity and porosity.

\section{Seismic Derived Porosity Maps}

Seismic-derived porosity maps for the Grayburg A and B zones are shown in figures 10 and 11. These zones comprise the upper part of the Grayburg and are reservoirs for the significant historic production. The complex areas of high porosity within the A zone are adjacent to areas of much lower porosity. Water injection wells placed in the low porosity areas might not be effective for moving fluids toward producing wells. A significant trend in the A zone is the southwest oriented low porosity area that coincides with the structural break in the southeast part of section 36 (see Figure 5). As a barrier to fluid flow, the engineering simulation was reoriented to parallel the anomaly. The $B$ zone is, on average, less porous than the $A$ zone, but was included in the fluid simulation. A brief supplemental study of the gas-to-oil ratios measured for the Grayburg production was made from early records. GOR values in section 36 , west of the A zone porosity barrier are about one-fourth of the values on the downdip side of the barrier in section 31. A discontinuity of the A zone reservoir is strongly suggested by that relationship. The barrier may be a stratigraphic trap to fluid movement, demonstrated by high GOR values at the updip limit. Waterflood attempts across such a barrier would be pointless.

The seismic-derived porosity data were exported as spreadsheet values of $x, y$, and porosity to engineering software that contains data from historic production of oil, gas, and water, zone thicknesses, and other relevant parameters. The more densely defined porosity distribution contributed to building an optimum reservoir model. The objectives of that model are to determine remaining oil in place and optimum ways of extracting it. The reservoir model is qualified by the match with production history. This model is the basis of understanding waterflood effectiveness and of planning recompletions, new wells, and abandonments.

The surface seismic tool holds great potential for characterizing carbonate reservoirs in the Permian Basin. Although specific local problems must be addressed in the approach to analyzing the data, Inversion Modeling is an important step in converting seismic data into an intuitively useful form. 
Ultimately, the multi-disciplinary approach is necessary to produce hundreds of millions of barrels of oil already discovered.

\section{GEOLOGY}

As discussed in the GEOPHYSICAL section, there is a significant variance in the gas-to-oil ratios for the Grayburg " $A$ " interval in the wells drilled during the initial development of the oil field. The high GOR values (greater than 1000) occur in a trend that coincides with a permeability barrier seen on the seismic-derived porosity map, and in an area on the Brock lease where the map indicates low porosity (Figure 10). This variation was previously noted, and compared with the Initial Potentials for these wells (see Phase One Final Report). The lack of highquality log data, however, precluded reaching firm conclusions. Once the permeability barrier was identified on the seismic-derived porosity map, it's significance to the history match and engineering modeling was realized. To evaluate if the barrier was effective in both reservoir production and geologic time, the only benchmark is the GOR data. It had been postulated from the inception of the study that there was a break in slope of the shelf where the permeability barrier has been identified. Geologically, there is a panel of dip, across which it is difficult, if not impossible, to correlate log units. In addition, the Grayburg interval down dip of the break thickens rapidly. This thickening is also seen on the seismic profiles as a wedge of sediments at or near the top of Grayburg. The high GOR's are found in wells that are immediately down dip (in section 31) of the permeability barrier. This would indicate that the down dip wedge of sediments are separated from the up dip sediments by the permeability barrier, and have reached equilibrium separately. As there are no cores available from the down dip section, it is still difficult to draw sequence stratigraphic conclusions. The down dip sequence may be correlative with the sequence discussed by Ruppel and Bebout (1996) in their study of the South Cowden Field to the southeast, and the up dip sequence (in section 36 , Foster field) represents a high stand interval not identified in South Cowden. Geologically, the recommendation to the Engineer is to treat the up dip and down dip sections.as separate reservoirs.

\section{Water Analyses}

In 1996, it was determined that poor quality "mixed "injection waters were causing 75 micron filters to be plugged on a regular basis. For injection waters not to cause formation damage, the waters should be capable of passing through 10 microns filters (if not 5 microns). Based on buildup tests which indicate severe skin damage in many wells, the injection water has obviously caused reduced injectivity, as the large-volumes of solids were plugging pore throats at the well bore/reservoir interface. The solids problem has been addressed (see 1996-1997 Annual Report) with changes in the surface facilities.

The concentration of Total Dissolved Solids (TDS) in the injection water, however, was not effected by the changes in the surface facilities. The large concentration of TDS in the injection water has resulted in potentially damaging changes in the formation water chemistry. The primary evidence for this is the 
very high scaling tendencies seen in the produced water following a number of recent refracs. The water chemistry "problem" is being attacked by eliminating the various "make up" waters, and returning the system to a better balance between the injected and connate water.

As a result of the recent restimulation of a number of wells, a larger volume of water is now available for re-injection. By eliminating the use of "make up" waters, the TDS of the injection water has dropped from 74,000 PPM to 58,000 PPM over the past two years. Although this produced water still represents a mix of waters, it is within the range of Grayburg and San Andres formation waters. Before an understanding of the flood water chemistry can be developed, it is necessary to determine, if possible, the original composition of the upper Grayburg, lower Grayburg, San Andres, Canyon and Ellenburger formation waters. The base line data would be extremely useful in identifying the source of, and changes in, injection and produced waters.

\section{Virgin Formation Waters}

Soon after the project began, it was discovered that more than 320 samples of produced and injected water from the study area had been collected and analyzed. The oldest complete analyses date from 1962, at the inception of the waterflood (there were two partial water analyses dating from 1940). Samples began to be collected periodically, at least yearly, from both producing and water injection wells during the 1970's and continued to the present. It became obvious that over time, any and all available water was injected. During the 1960's local water sources, producing from the Ogalalla (10,743 PPM TDS), Santa Rosa (3,873 PPM TDS), and a "water well" (1,050 PPM TDS) were utilized. In 1966, a sample of injected water contained 6,299 PPM TDS, significantly fresher than either the Grayburg or San Andres. Two produced water analyses from that same time contained between 13,500 PPM to 14,800 PPM, indicating that the fresh injection water had already changed the water chemistry in the formation. During the late 1970's and 1980's, Canyon (Pennsylvanian), Ellenburger (Lower Ordovician), and "Hendricks Reef Water" (upper Permian) waters were being used as "make up water". The "Virgin Formation Waters" chart (Figure 12) indicates the range of TDS in these waters. Hendricks Reef Water contains half the TDS of original upper Grayburg water. Canyon water contains almost five times the TDS of the upper Grayburg and twice the TDS in the San Andres. Ellenburger produced water contains four times the TDS of virgin upper Grayburg water.

The upper Grayburg virgin formation water chemistry is from samples taken at the inception of the water flood. The lower Grayburg water is an average of samples taken from isolated tests of the interval during this study (1996-1998). The lower Grayburg was tested separately in the Witcher \#2 deepening, and the Witcher \#12, Foster \#11, and Foster-Pegues \#11 new drills. Water samples from those tests are remarkably consistent (Figure 13). 
The San Andres was tested separately in the Witcher \#2, Witcher \#12, and Foster \#11 during this study (1996-1998). As in the lower Grayburg tests, the water chemistry was remarkably consistent (Figure 14). One other point of interest is that the lower Grayburg and San Andres in these wells do not appear to have been contaminated by flood water. This is as expected, as the wells are not near locations where lower Grayburg and/or San Andres injection has taken place. Hendricks Reef Water analyses date from 1971 and 1975, Canyon samples were collected from various wells in the study area from 1981 to 1996. The Ellenburger sample was collected from a well in the study area in 1998.

Based on the original history match, over $85 \%$ of the injected water was pumped into the upper Grayburg, less than $10 \%$ into the lower Grayburg/San Andres. It is estimated that $5 \%+1-$ of the water was injected into the lower Queen (not part of the reservoir) via open holes with casing set above the top of the upper Grayburg. Historically, the overwhelming preponderance of the injection water has been cycled through the upper Grayburg, which was originally the primary waterflood target and has become so again.

The samples of injection water from 1977 through 1996 showed (Figure 15) a steady increase in Sodium and/or Potassium (reported together), Calcium (as $\mathrm{Ca}$ ), Magnesium (as $\mathrm{Mg}$ ), Chloride (as $\mathrm{Cl}$ ), Sulfate (as SO4), bicarbonate (as $\mathrm{HCO}$ ) and TDS. A similar increase in the major cations, anions, and TDS were also seen in the produced waters (Figure 16). Although all the major cations and anions have changed over time, the TDS, sodium, and chloride are most consistent. Ratios such as calcium to magnesium and calcium to chloride are also used to differentiate between formation and flood water. The TDS will be reported on here as that value which has become the "shorthand" analyses most often discussed amongst the study participants.

In addition to the 320 water samples analyzed prior to the inception of the project, 210 new water samples have been collected and analyzed starting in November 1995. The potential uses of this data set were beginning to be realized (see 1996-1997 Annual Report, p.48) at this time and, as a result, periodic sampling of each well was initiated. In addition, water samples were taken prior to and following any change in a wells status (setting CIBP's, refracturing, etc.). The produced water analyses are now being used as a real time indicator of the success or failure of day-to-day field operations. Some of the questions that are being addressed are:

- What is the source of produced water? Virgin formation, flood water or a mix?

- Was the setting of a CIBP successful in isolating a zone or zones?

- Was a fracture stimulation successful in producing from a single zone (Pipeline Frac) or multiple zones (conventional frac)?

- What is the cause of a sudden change in production?

- Is water being coned up from a deeper reservoir? 


\section{Source of Produced Water}

The Brock \#5 serves as an example of how water analyses can be used to determine the source of produced water. The upper Grayburg in the Brock \#5 was refractured in August (see ENGINEERING). The water analyses from before (51,700 PPM TDS) and after (42,700 PPM TDS) the procedure are significantly different and indicate the frac contacted previously under-produced, though somewhat flooded, reservoir. Three water samples taken 8/24, 8/31, and 9/21 (Figure 17) indicate a slow increase in the TDS from 42,700 to 44,300 to 46,000 PPM. This may indicate an increase in percent of waterflood water as the reservoir further from the well bore, and closer to an injector, is drained. The San Andres is not considered to be a source of the water with elevated TDS in the well.

\section{Successful Isolation with CIBP}

The Brock \#6 is an example of a successful plug back to abandon the lower Grayburg/San Andres, prior to an attempted restimulation of the upper Grayburg. Before the plug back, the well produced 7 BOPD, 33 BWPD, and 2 MCFPD. After the plug back, the well produced 5 BOPD, 9 BWPD, and 1 MCFPD. Although it appeared this procedure was successful, some of the wells are communicated behind pipe between the upper Grayburg and the deeper zones. Prior to attempting a refracturing of the Brock \#6, it was necessary to determine if the zones were in communication as it is imperative to avoid failed restimulations, and hence, keep costs low.

Two independent methods provide data on the success of a plug back. Water analyses can identify the source of produced water and bottom hole pressure tests identify how many zones are open. Samples of produced water were collected prior to and after the plug back, and were analyzed within days of collection. Although a bottom hole pressure test provides a large volume of engineering data, it can take up to a month to complete, necessitate shutting in the well, and might still produce ambiguous results. The water chemistry analyses, although subject to interpretation, can be used to provide an answer within a few days of the plug back. The bottom hole pressure tests have, in the majority of cases, supported the conclusions drawn from the produced water analyses. In those cases where a bottom hole pressure test with a high confidence level conflicts with the water analyses, the bottom hole pressure test is considered to be more reliable.

In the Brock \#6 (Figure 18), the TDS had dropped from 47,200 PPM before the plug back to 38,900 PPM after, indicating that the plug back was successful. Shutting off the lower Grayburg/San Andres water, with an estimated 55,000 to 64,000 PPM, should result in a drop of the TDS in the produced water. The water analyses indicated that the CIBP had successfully isolated the lower Grayburg and San Andres. This conclusion was later confirmed by the bottom hole pressure test. 


\section{Unsuccessful Isolation with CIBP}

The Foster - Pegues \#7 is an example of an unsuccessful attempt to plug back to abandon the San Andres and lower Grayburg. Before the plug back, the well produced 5 BOPD, 51 BWPD, and 1 MCFPD. After the plug back, the well produced 5 BOPD, 55 BWPD, and 1 MCFPD. The fact that the production did not significantly change from before, to after the plug was set cannot be used to support either a successful or unsuccessful procedure. The analyses of produced water (Figure 19) from before (TDS $=64,800$ PPM) and after (TDS $=66,300$ PPM) the plug back indicate a small change in the produced water. Based on the water analyses, it appears that the upper Grayburg is still in communication with the lower Grayburg/San Andres behind pipe. The change may indicate that the relative percent of upper Grayburg waterflood water may have increased, albeit slightly, as a result of forcing the lower Grayburg/San Andres water to take a more tortuous path behind pipe.

A bottom hole pressure test was conducted, which confirmed that the well was producing from two zones. This well has been dropped from the queue for refracturing until such time as it would be economic to squeeze the lower zones prior to refracturing the upper Grayburg.

\section{Successful "Pipeline" Frac}

Following a prolonged production test of the San Andres in the Witcher \#2, it was decided to plug back with a CIBP and test the lower Grayburg. The San Andres had IP'd for 88 BOPD, 225 BWPD, and 18 MCFPD. Within three months, the production had dropped to $4 \mathrm{BO}, 32 \mathrm{BW}$ and 2 MCFPD after producing $3200 \mathrm{BO}$ and 12,500 BW, and $850 \mathrm{MCF}$. Log calculations indicated highly porous "wet" zones above and below the San Andres pay. Any conventional frac treatment of the lower Grayburg would "grow" down into the San Andres. It was decided to attempt a "pipeline" frac in order to stay in zone in the lower Grayburg. In Fig. 20, the results of the water analyses of the San Andres and lower Grayburg demonstrate that the "pipeline "frac was successful in staying in zone. The San Andres, with 63,000 PPM TDS, was successfully isolated from the lower Grayburg with 37,000 PPM TDS. After six months, the lower Grayburg TDS had not changed, eliminating the possibility that the San Andres water was being coned up into the lower Grayburg.

\section{Successful Multi-zone Completion}

The Witcher \#12 is an example of a successful multi-zone (lower Grayburg/San Andres) completion confirmed by water chemistry analyses. The lower Grayburg and San Andres zones were cored in this well as part of a program to better understand these reservoirs. There is a highly porous, wet interval immediately below the base of the San Andres pay. Based on the core and isolated production testing, the San Andres pay, although porous, lacked enough permeability to produce economic quantities of oil without a fracture stimulation (see Annual Report 1996-1997). A conventional frac, centered on the lower Grayburg pay was proposed with the intent of allowing the fractures to grow 
down onto the San Andres pay, but not deep enough to produce the water leg below. A San Andres water sample (Figure 21) taken during the isolated production test contained 60,200 PPM TDS. After the fracture stimulation, The produced water contained 48,900 PPM TDS. This represents a 50/50 mix of lower Grayburg and San Andres produced waters. The conclusion is that the procedure was successful in fracture stimulating both the lower Grayburg and San Andres. Water analyses indicate that within three months the produced water TDS had risen to 62,200 PPM, indicating that the produced water was now entirely San Andres in origin, or conversely that the amount of Grayburg produced water had dropped significantly.

\section{Cause of a Sudden Change in Production}

Results of Brock \#6 water analyses can be used as an example of how water chemistry can identify the cause of a sudden drop in production. The Brock \#6 was refractured during the second quarter 1998. After the production had stabilized at 33 BOPD, 199 BWPD, and 12 MCFPD, it declined rapidly to 23 BOPD, 169 BWPD, and 9 MCFPD. Based on the water chemistry analyses, scale was suspected as the cause of the production decline. A scale squeeze resulted in an increase to 28 BOPD, 191 BWPD, and 9 MCFPD. The production again declined rapidly and a second larger scale squeeze was performed. After an initial increase, the production again declined rapidly to the low 20 's. It was feared that the scaling would continue to cause the production to decline.

Water samples had been taken (Figure 18) following the frac, after the first production drop, and after each scale squeeze. Produced water analyses indicated that the produced water, after refracturing, had high scaling tendencies and a high $\mathrm{pH}$ (7.6 to 7.8). An evaluation of changes in water chemistry between the post-frac and post-scale squeeze water sample, and the post production drop samples was undertaken. It can be concluded from the data set that there are two zones in the upper Grayburg producing different waters. The water associated with the primary zone, which produces the 23 BOPD, has 38,200 PPM TDS, whereas the water associated with the scaled zone had 55,000 PPM TDS and much higher scaling tendencies. It was postulated that the 'good zone' would not scale off and the production would stabilize in the low 20's. To date the well has continued to produce between 19 and 23 BOPD. No additional scale squeezes have been attempted, as the potential benefits were considered noneconomic. As the scaled zone might be capable of contributing some hydrocarbons, and is not considered a potential thief zone, it was neither squeezed off nor isolated and left open to the well bore.

\section{Coned Water}

The Foster-Pegues \#11 was drilled as a lower Grayburg test in 1996. Based on tests in the area, the San Andres at this location is believed to be wet as the reservoir drops below the oil/water contact to the southeast. The lower Grayburg pay in the well is within $75^{\prime}$ of the top of the San Andres. A successful fracture stimulation resulted in a flowing IP of 106 BOPD, 34 BW, and 34 MCFGPD. 
Water samples taken after the completion (Figure 22) indicated a lower Grayburg (37,600 PPM TDS) only produced water. A water sample taken six months later contained 41,400 PPM TDS, indicating a slight increase in San Andres water. Eight months after the completion, the TDS had risen to 50,400 PPM. Two samples taken 29 months after the completion contained 55,300 PPM TDS. This indicates a gradual increase in the San Andres component of the produced water. The well is presently producing 16 BOPD, 22 BWPD, and 2 MCFGPD. The fact that the water production has only dropped by half, whereas the oil has had a seven fold declined, indicates that water is probably coning up from the "wet" San Andres. No injection into the lower Grayburg was reported in this area.

\section{Brock Lease Water Analyses}

Based on the original simulation, an area of high oil saturation exists on the Brock lease extending from the Brock \#5 on the southeast to the Brock \#13 on the northwest. The Brock lease became a target for enhanced recovery, after the Brock \#13, was successfully recompleted in the upper Grayburg. The Brock \#13 had been one of the original workover recommendations (see First Quarter 1996 Report) for a plug back from the lower Grayburg/San Andres. After evaluating the Brock \#13, a suite of bottom hole pressure tests of short duration ( 3 to 5 days) were run. These tests proved to be not long enough to evaluate the reservoirs, and are considered unusable. As part of a revised testing program to evaluate the Brock lease, water analyses and a new round of bottom hole pressure tests, conducted before and after any plug backs from the San Andres and lower Grayburg, were recommended. Of the eight producing wells on the Brock lease, five (Brock \#5, Brock \#6, Brock \#7, Brock \#8, and Brock \#10) wells are considered re-frac candidates.

The produced, and injection waters for all the Brock wells were sampled and analyzed. The produced water TDS (Figure 23) are in the 38,000 to 58,000 PPM range. All of the wells are completed in the upper Grayburg and lower Grayburg/San Andres, with the exception of the Brock \#13, previously plugged back to the upper Grayburg, and the Brock \#12, completed in the lower Grayburg but receiving flood support from an offset upper Grayburg injector. In 1990 the injection water for the Brock lease contained 83,300 PPM. By 1997, as a result of a program to rehabilitate the injection system, the injection water contained only 64,500 PPM. Although the producing wells in the Brock lease are producing some injection water, they are certainly not being efficiently waterflooded.

\section{Foster-Pegues Water Analyses}

In conjunction with bottom hole pressure tests, water analyses of the produced water from the Foster-Pegues \#7, Foster-Pegues \#8, and Foster-Pegues \#9 were taken prior to, and following, the setting of a CIBP to plug the wells back to the upper Grayburg.

The Foster - Pegues \#7 plug back was discussed above. 
The Foster-Pegues \#8 was plugged back to abandon the lower Grayburg/San Andres. Before the plug back, the well produced 2 BOPD, 16 BWPD, and 1 MCFPD. After the plug back, the well produced 2 BOPD, 12 BWPD, and 1 MCFPD. The analyses of the produced water from before (TDS $=63,500$ PPM) and after (TDS $=68,500$ PPM) the plug back indicate little change in the produced water. The TDS of the produced water after the plugback $(68,500$ PPM) is higher than average San Andres water (64,000 PPM) and similar to 1996 injection water (72,000 PPM). The fact that the production did not change from before to after the plug was set, indicates the lower Grayburg/San Andres were not contributing to the production and may actually have been a "Thief Zone". The bottom hole pressure test from before the plug back indicated two zones were open in the well. The bottom hole pressure test run after the plug back indicated only one zone was open in the well. In this case, the water chemistry data is ambiguous and the bottom hole pressure test data definitive. The well is scheduled for refracturing in October.

The bottom hole pressure test run on the Foster-Pegues \#9 after the plug back indicates very low pressure. The Foster-Pegues \#9 is located at the margin of the no flow trend (see geophysics First Quarter Report 1998) and may lack sufficient injection support. The well will not be refractured until injection support is established and the bottom hole pressure increased. A tracer survey to determine flow paths of injection water on the Foster-Pegues lease is contemplated.

\section{ENGINEERING}

\section{Production for 1997}

During January, the monthly oil, gas, and water production for each well, for 1997, was updated for use in the updated simulation during January. Based on periodic three day production well tests, monthly lease totals, and workover reports, production was allocated to each producing well in section 36 . Monthly injection for each injector was determined from lease reports. The data were input into a spreadsheet where production is allocated to each zone, then used in the simulation.

\section{Simulation Results}

Flow models were built specifically to test the seismic-derived porosity maps (see Geophysics). After reviewing the seismic derived porosity map, it became apparent that the simulation grid needed to be rotated approximately 45 degrees to match a no-flow boundary (a very low porosity trend parallel to a break in slope in the Foster-Pegues lease). The original simulation grid was oriented parallel to the section lines as the "geology only" porosity map was not of sufficient detail to define the no flow boundary. The flow models considered only section 36. Separate models were built for each upper Grayburg layer (A, B, and C). The purpose was to directly compare the oil in place (OIP) for a model built from the seismic-derived porosity map to the OIP for a model built from well 
values and then history matched. Initial comparison indicated that the OIP from the seismic-derived porosity maps was about $50 \%$ greater than the OIP from the history matched model. The velocity to porosity transform to create the seismic maps was adjusted until the values of OIP were within $20 \%$. At that point the conventional history matching process started.

Although similar to the original simulation, the reoriented simulation exhibited significant differences in the distribution of present day water saturations. A suite of bottom hole pressure Tests was begun on all wells that have not already been refractured. The new simulation will be run again in the future when the pressure buildup tests, produced water analyses, additional production and data from additional refracs are completed and analyzed.

The upper Grayburg is now the primary target in the study area. Completions in the San Andres have demonstrated the limited nature of the reservoir. As previously discussed (see 1996 - 1997 Annual Report), the karst event at the end of the San Andres has compartmentalized the reservoir in this portion of the platform. The lower Grayburg has also been isolated and tested in a number of wells and appears to be a poor waterflood target due to low permeability and poor injectivity. CIBP's are being set above the San Andres and lower Grayburg zones so that, in the future, the zones can be re-entered. In most of the wells, the lower Grayburg and San Andres were completed through a single set of perforations and a single frac. Therefore, we will refer to the lower Grayburg and San Andres as a single unit, the lower Grayburg/San Andres. The upper Grayburg waterflood (A, B, and C zones) has become the focus of the project. The high confidence level in the upper Grayburg seismic derived porosity maps re-enforces the decision to enhance the existing waterflood.

\section{Field Engineering Objectives}

Together with the continuous testing and monitoring of bottom hole pressures, individual well production, injection volumes, injection pressures, injection profiles and day to day operations, the engineering objectives of the year were to:

- Redirect the focus of the project on the re-alignment of the upper Grayburg waterflood

- Isolate the upper Grayburg in wells producing from multiple intervals

- Initiate a new bottom hole pressure testing procedure and program

- Implement recommendations derived from bottom hole pressure data.

\section{Re-Alignment of Upper Grayburg Waterflood}

The re-alignment of the upper Grayburg waterflood became the focus of the study area throughout 1998. Completion attempts in the San Andres had little success due to the limited nature of the reservoir. Tests in the lower Grayburg have indicated the interval to be productive. However, efforts to produce and waterflood both the upper and lower Grayburg in tandem have proven to be unsuccessful and inefficient due to the difference in reservoir characteristics. 
Thus, it was decided to plug back and isolate the upper Grayburg in all wells producing from multiple intervals and focus the project on re-alignment of the waterflood for the upper Grayburg. Figure 24 identifies wells currently producing from or injecting into the upper Grayburg. This table highlights the inefficiency of the so called "flood pattern" as it exists today. Although wells were originally drilled in a pattern adequate to flood the upper Grayburg, the present distribution of upper Grayburg emphasizes the need for the flood to be re-oriented, and available $P$ \& A'd and T \& A'd to be utilized. Prior to running the final re-oriented simulation (see simulation) it was necessary to gather as much additional information on the upper Grayburg as possible. Production tests, water analysis and a new suite of bottom hole pressure test were taken on all wells before and after isolating the upper Grayburg.

\section{Bottom Hole Pressure Testing}

Initial bottom hole pressure information obtained during the project was considered insufficient to aid in the re-alignment of the upper Grayburg waterflood. Previous bottom hole pressure tests were very short in nature. Generally, the tests lasted for a duration of three to four days and required a significant amount of extrapolation of the data. Due to the short shut-in periods, the results were uncertain and were considered unusable. Thus, a revised testing procedure and program was initiated for the project.

The new testing procedure consisted of continuously analyzing the data during the shut-in period. The tests were continued until a reasonable data set was collected for interpretation. On average, a good data set was collected after approximately 900 hours of shut-in time. Additionally, great attention and detail was given in the actual data gathering in the field.

\section{RECOMMENDATIONS}

As a result of the plug backs, production tests, and new suite of bottom hole pressure tests, it became apparent that although many of the wells have been a part of a waterflood for 30 years, their capability of producing fluids was poor. This is a result of the very short frac wing lengths achieved during a fracture program performed on the leases in the late 1970's and early 1980's. The fracture treatments pumped at that time consisted of 40,000 gallons of fluid and $20,000 \mathrm{lbs}$ of sand. Although the treatments achieved initial producing rates considered as successful, the relatively small treatments created short frac wing lengths resulting in rapid production declines.

Based upon high bottom hole pressures, short frac wing lengths and low total fluid production, it was recommended to initiate a re-stimulation program for the upper Grayburg. Seven wells were identified and recommended as re-frac candidates. Three wells, the Brock \#6, Brock \#5 and Foster-Pegues \#8 were re- 
stimulated in 1998. It was determined much larger treatments needed to be utilized to achieve greater frac lengths. The treatments, designed to obtain frac lengths of up to 180', averaged 28,000 gallons of fluid and 104,000 lbs. of sand. Producing rates in the wells prior to the treatment averaged less than twenty barrels per day. After initial declines following the treatments, the rates stabilized at over 150 barrels of fluid per day resulting in a seven fold increase in sustained production (see figure 25).

A standard water analysis costs $\$ 75.00$. A bottom hole pressure test is included as part of daily operations and is a no-cost item. The cost to analyze a bottom hole pressure is $\$ 425.00$. The production "lost" during a 30 day build up test is quickly recouped as flush production after the well is returned to production. A fracture stimulation, without new well equipment is $\$ 25,000.00$. All costs are approximate and fluctuate with the price of oil.

\section{Brock Lease}

In 1997 a CIBP was set above the lower Grayburg/San Andres formations in the Brock \#6. A bottom hole pressure test was performed in the first quarter of 1998 and analysis of the data indicated the well has a bottom hole pressure of 1584 psia, a frac wing length of less than 25 feet with no indication of effluence from the deeper intervals.

Because of the high bottom hole pressure, short frac wing length and total fluid production of less than fifteen barrels per day, the upper Grayburg in the Brock \#6 was re-fraced in April of 1998 with 34,104 gallons of 35\# cross linked gel and $98,260 \mathrm{lbs}$. of $16 / 30$ Brady sand. The well was put on pump and after recovering frac load produced at rates of 37 BOPD, 230 BWPD and 14 MCFPD. Production stabilized at 20 BOPD, 150 BWPD and 4 MCFPD after numerous attempts to combat scaling tendencies (see water analysis). Producing rates prior to the refrac were 3 BOPD, 8 BWPD and 1 MCFPD. A post frac draw down analysis performed on the well indicated a frac wing length of over 230 feet was achieved.

The Brock \#5 was a multi-zone completed well producing from the upper Grayburg and lower Grayburg/San Andres formations. Prior to setting a ClBP above the lower producing intervals a bottom hole pressure test was performed. The effluence of multiple zones could be seen in the analysis of the test data with evidence of cross flow between the intervals. After setting a CIBP between the upper Grayburg and lower Grayburg/San Andres, a bottom hole pressure test was taken. The test indicated a bottom hole pressure of 1660 psia, a frac wing length less that 30 feet and single zone production.

Based upon the test and total fluid production of less than ten barrels per day, the upper Grayburg in the Brock \#5 was re-fraced in August of 1998. The frac consisted of 24,900 gallons of $35 \#$ cross-linked gel and $97,500 \#$ of $16 / 30$ sand. In an attempt to combat the scaling problems encountered after fracture treating the Brock \#6, a scale inhibitor in the form of frac beads was included throughout 
the sand laden fluids during the re-stimulation. Production prior to the job from the well was 4 BOPD, 6 BWPD and 1 MCFPD. Initial producing rates after recovering frac load was 75 BOPD, 180 BWPD and 18 MCFPD. The well stabilized at rates of 40 BOPD, 145 BWPD and 6 MCFPD with little indication of scaling problems. Information taken from a post frac drawdown analysis showed a frac wing length of 120 feet.

The bottom hole pressure test on the Brock \#8 and Brock \#10 were inconclusive due to mechanical failures and excessive wellbore storage during the shut-in periods. These wells were scheduled to be re-tested.

The Brock \#7 is a directional well completed in the upper Grayburg only. Analysis of the pressure test indicated the well has a bottom hole pressure of 1087 psia, single zone influence and a frac wing length of 32 feet. This well was recommended to be re-frac at a later date.

\section{Foster-Pegues Lease}

The Foster-Pegues \#7, Foster-Pegues \#8 and Foster-Pegues \#9 all produced from the upper Grayburg and lower Grayburg/San Andres formations. Initial bottom hole pressure tests in all wells showed evidence of dual zone completions. After setting CIBP's between the upper Grayburg and lower Grayburg/San Andres formations in the First Quarter of 1998, additional pressure tests were performed on the three wells.

The test data from the Foster-Pegues \#7 showed conclusive evidence of dual zone effluence, even though a CIBP was in place. This indicates the upper Grayburg and lower Grayburg/San Andres are in communication behind pipe. The bottom hole pressure test run after the bridge plug was set had higher pressure, indicating strong upper Grayburg influence, and argues that the communication is inefficient. The well has been given a low priority and will not be considered for fracture stimulated till late next year.

Analysis of the Foster-Pegues \#8 test indicated the well had waterflood support with a bottom hole pressure of 2550 psia, which is equal to the bottom hole pressure of offsetting injection wells. There was no evidence of a fracture or dual zone influence.

Although the producing water oil ratio was relatively high, the Upper Grayburg was re-fraced in the Foster-Pegues \#8. The interval was fracture treated with 25,174 gallons of $35 \#$ cross-linked gel and $118,580 \#$ of $16 / 30$ sand. Again, a scale inhibitor in the form of frac beads was incorporated throughout the job. Production rates prior to the re-stimulation were 2 BOPD, 15 BWPD and 1 MCFPD. After recovering the frac load, the production rates stabilized at 22 BOPD, 450 BWPD and 1 MCFPD with no sign of decline. 
The test on the Foster-Pegues \#9 was inconclusive. However, the test did indicate a very low bottom hole pressure and lack of waterflood support. This supports the no-flow boundary on the seismic derived porosity map, which intersects the lease at this location.

\section{H. C. Foster Lease}

During the Third Quarter of 1998 bottom hole pressure tests, were performed on the H. C. Foster \#7, H. C. Foster \#8 and H. C. Foster \#9.

The H. C. Foster \#7 produced from the upper Grayburg and lower Grayburg/San Andres. The pressure test indicated the well has a bottom hole pressure of 1890 psia with some indication of a dual zone completion. It was recommended to set a CIBP between the producing intervals and re-test. However, a review of the well history indicated the two zones communicated behind pipe when the well was fraced in 1981. The plan for this well is to squeeze the upper Grayburg perforations to eliminate the communication, then reperforate and refracture the upper Grayburg.

A pressure test was conducted after setting a CIBP between the upper Grayburg and lower Grayburg/San Andres in the H. C. Foster \#8. The test showed very little frac wing length, single zone influence and a bottom hole pressure of 1490 psia. Due to low production rates the well was recommended to be re-fraced at a future date.

The H. C. Foster \#9 produces from the upper Grayburg and lower Grayburg/San Andres. The pressure test showed the well has a bottom hole pressure of 1625 psia. An attempt was made to set a CIBP between the producing intervals. However, collapsed casing was encountered at the base of the upper Grayburg. Thus, any further plans for this well were canceled

\section{Witcher Lease}

During the Second Quarter of 1998 build-up tests were performed on the Witcher \#6 Witcher \#7, Witcher \#5 and Witcher \#11.

The bottom hole pressure test on the Witcher \#6 was quantitatively meaningless. The test was still in wellbore storage-cross flow at the end of the test period.

The pressure test on the Witcher \#7 showed the well had a bottom hole pressure of 2000 psia with waterflood support. This coincides with producing rates of 15 BOPD, 210 BWPD and 4 MCFPD. There were no recommendations for this well.

The Witcher \#5 produces from the upper Grayburg. The pressure test gave indication of little flood support with a low bottom hole pressure of 630 psia, a frac wing length of 38 feet and single zone influence. There are no recommendations for this well at this time. 
The Witcher \#11 was tested prior to setting a CIBP between the upper Grayburg and lower Grayburg/San Andres. The pressure test gave evidence of single zone influence only, a bottom hole pressure of 1145 psia and a short frac wing length of 27 feet. A CIBP was set between the producing intervals. A follow up test has not, as yet, been performed. 


\section{RESULTS}

As a result of the refocus of the project on the upper Grayburg seven wells were identified and recommended as re-frac candidates. During 1998 three of the wells were re-stimulated. Prior to the workovers, total production from the three wells was $11 \mathrm{BO}, 29 \mathrm{BW}$ and $3 \mathrm{MCF}$. Production from the wells after the re-fracs peaked at $135 \mathrm{BO}, 875 \mathrm{BW}$ and $22 \mathrm{MCF}$ and has since stabilized at $87 \mathrm{BO}, 684$ $\mathrm{BW}$ and $16 \mathrm{MCF}$. This represents a 7 fold increase in total sustained production from the three wells.

A result of the well work has been the arrest of the decline for section 36 seen in the years prior to the implementation of the project. Since June of 1993, the production from the project area has risen to 7,500 BOPM from 6000 BOPM. During 1997 the production peaked at over 10,000 BOPM (see figure 25). To date, it is estimated an additional 125,000 barrels of oil have been recovered as a result of work performed during Phase I and Phase II of the project.

The accomplishments and success of the work performed during1998 supports the conclusions from Phase I of the project. Through the integration of modern engineering methods, geological and geophysical data, it is possible to recover economic amounts of oil from very mature reservoirs.

\section{TECH TRANSFER EVENTS}

West Texas Geological Society 1997 Fall Symposium, "Permian Basin Oil and Gas Fields: Turning Ideas into Production", Midland, Texas, October 31, 1997. Two presentations were made, complementing the geological and geophysical conclusions of the project to that date. R. C. Trentham presented the geology and engineering in a talk entitled "How an Independent Operator can Integrate Engineering, Geophysics, and Geology in a Reservoir Study. The Grayburg/San Andres of Foster and South Cowden Fields, Ector County, Texas", and W. C. Robinson presented the geophysics in a talk entitled "Practical Mapping of Lithology and Rock Properties using Analyses of Seismic Inversion Models".

A presentation titled, "How An Independent Can Integrate Geology, Geophysics, And Engineering To Enhance Reserves In An Old Field", was made by R. C. Trentham to the Kansas Geological Society on November 5, 1997 in Wichita, Kansas.

Trentham, Robert C., W.C. Robinson, R.M. Weinbrandt, 1998, The Use of Core in an Integrated 3D Seismic, Geological, and Engineering Study of the Grayburg/San Andres of Foster and South Cowden Fields, Ector County, Texas. In. E.L. Stoudt, D.W. Dull, and M.R. Raines eds., Permian Basin Core Workshop

- DOE Funded Reservoir Characterization Projects: Permian Basin Section 
SEPM Core Workshop, Publication 98-40, 22 pages. Presented February 26, 1998.

Weinbrandt, Richard M., R.C. Trentham, W.C. Robinson, 1998, Incorporating Seismic Attribute Porosity Into a Flow Model of the Grayburg Reservoir in the Foster - South Cowden Field SPE\#39666. Presented at the 1998 SPE/DOE Improved Oil Recovery Symposium. Tulsa, Oklahoma, April 19-22,1998.

Proceedings, vol. 1, p.115-128. Presented orally at the Symposium, April 22, 1998.

A class from Midland College was invited to visit Laguna's office for a review of the geology and geophysics, and the use of computers in the study methodology. About twelve students and their professor attended the seminar.

\section{REFERENCE}

Ruppel, S., and Bebout, D., 1996, Effects of Stratal Architecture and Diagenesis on Reservoir Development in the Grayburg Formation: South Cowden Field, Ector County, Texas: Fossil Energy, U.S. Department of Energy, annual report, $\mathrm{DOE} / \mathrm{BC} / 14895-10,80$ pages.

\section{ACKNOWLEDGMENTS}

We would like to acknowledge James J. Reeves and Hoxie W. Smith for conceiving and managing the DOE study and for being responsible for the geophysical study until April 1996. Since that date, William C. Robinson has been responsible for reprocessing and reinterpreting the seismic data and for the geophysical study. Also since that date, Robert C. Trentham has been responsible for project management. 


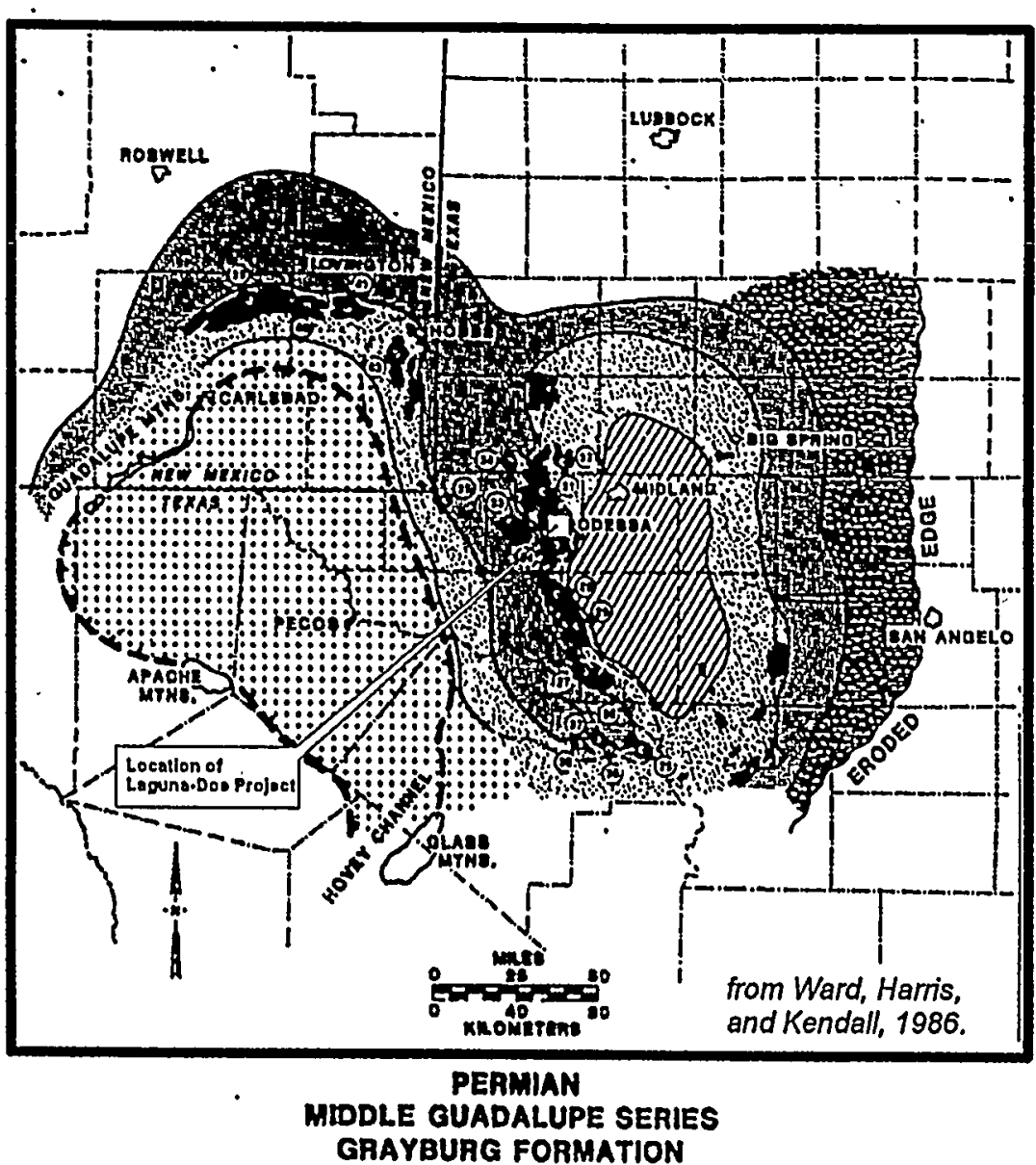

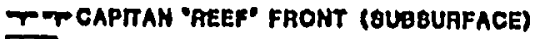
DELAWAAE BABIN-CHERAY CANYON FoAmATION BABINAL BAHDBTONE, OLT, BHALE AND LIMEOTONE

73 DOLOMITE

--- oUtLime centaAl oABm platform

(C) OILFIELDO LIOTED IN TAULES

SIMPLIFIED QEOLOQIC MAP OF THE QRAYBURO FORMATION, PEAMIAN BASIN, SHOWHNO THE LOCATIONS OF PRODUCING FIELDS. SEE TABLE 2 IN APPEN. DIX FOR DETALLD DESCRIPTIONB OF THE NUMBERED FIELDS.

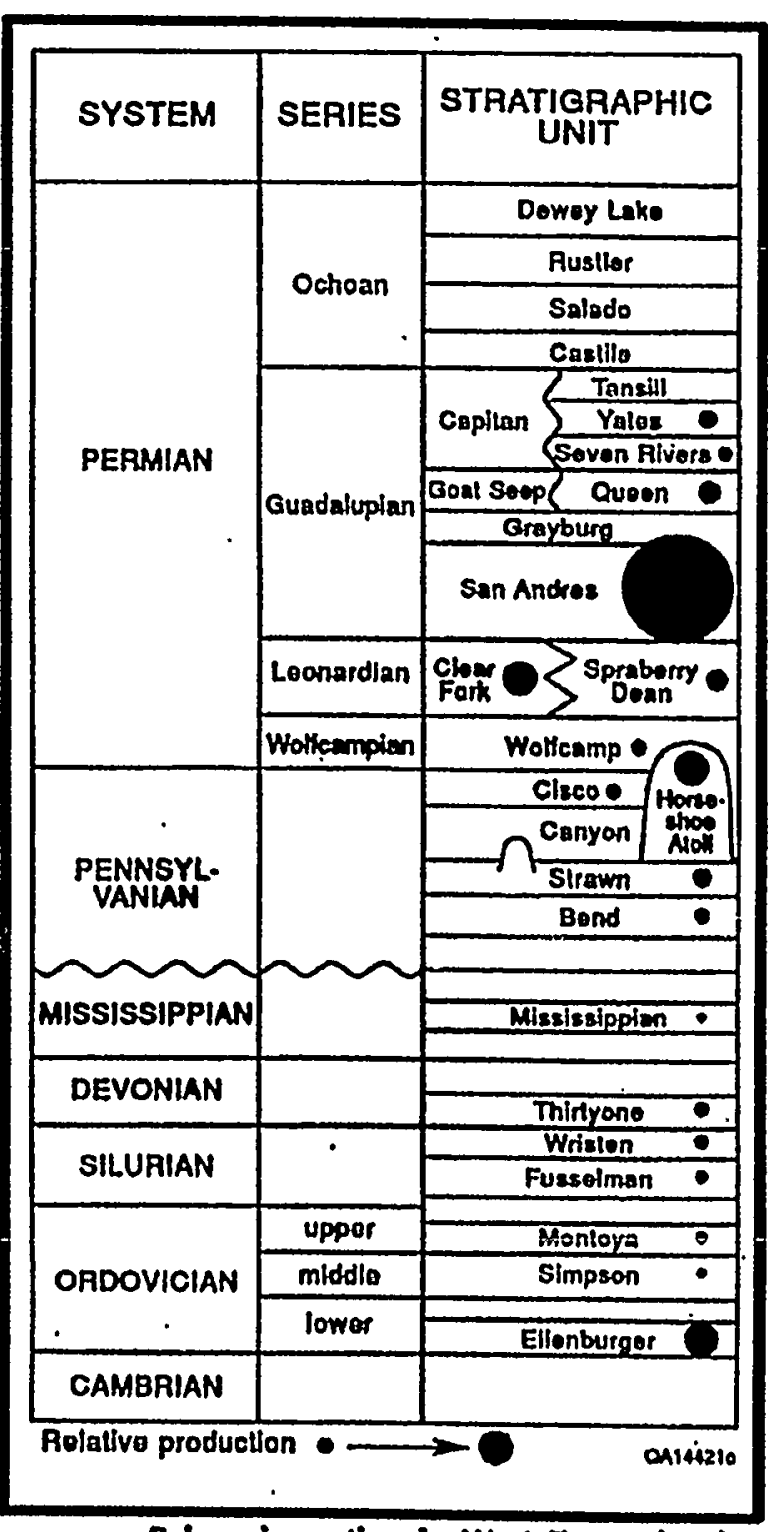

Paleozolc section in West Texas showing relative importance of oll producing unit (from Galloway and others, 1983).

Figure A. Location Map for the Laguna-DOE Project and Stratigraphic Column. 


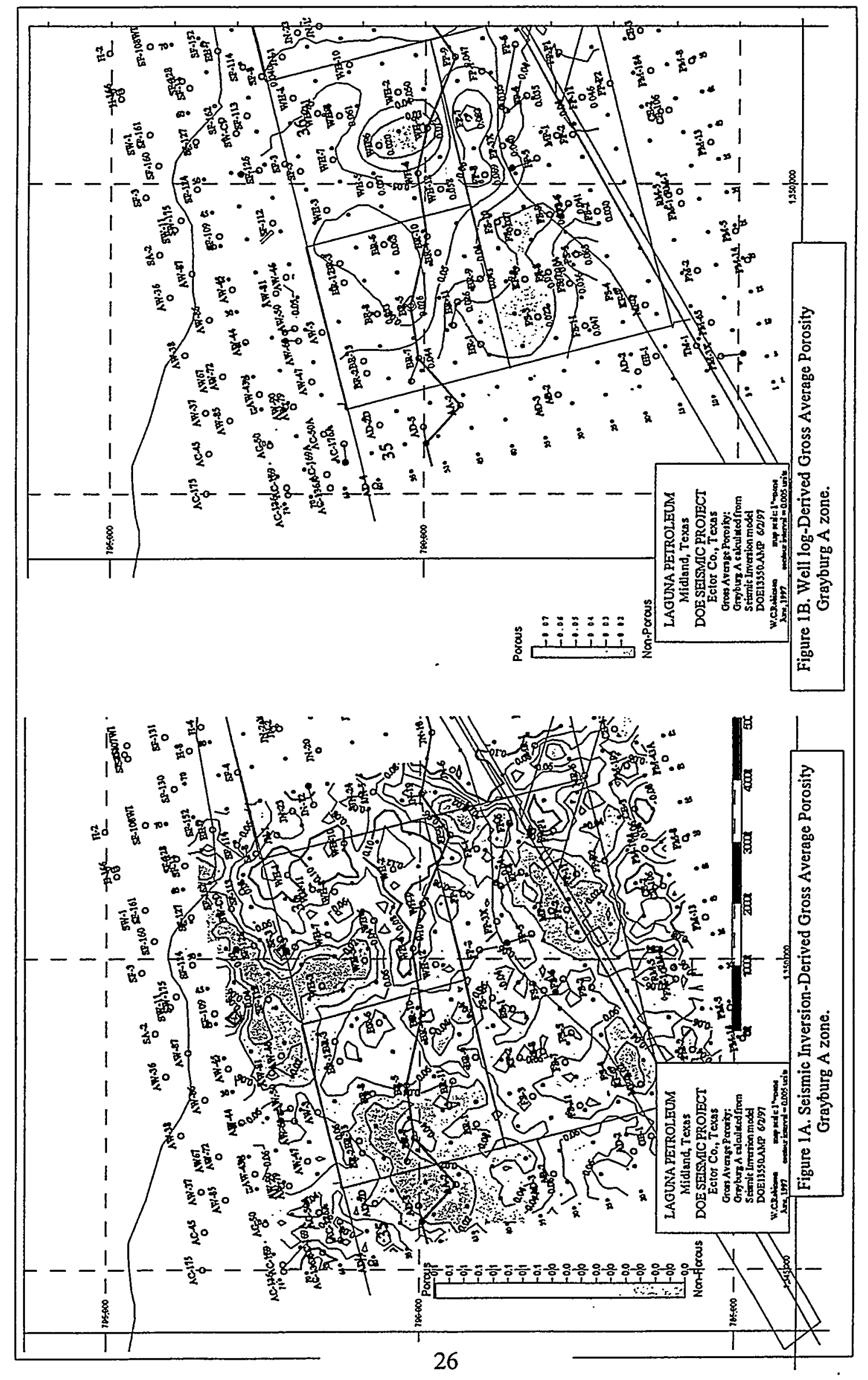




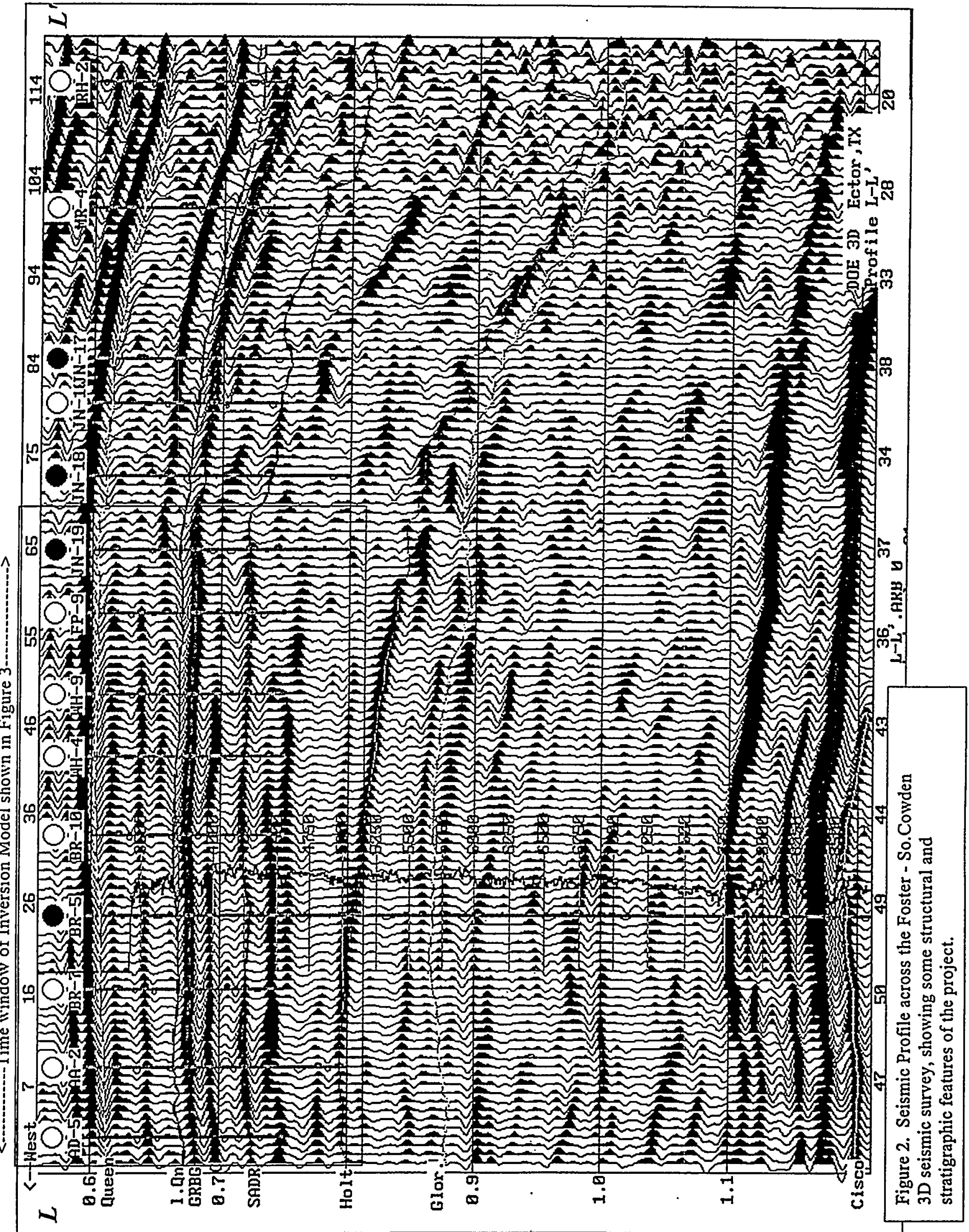




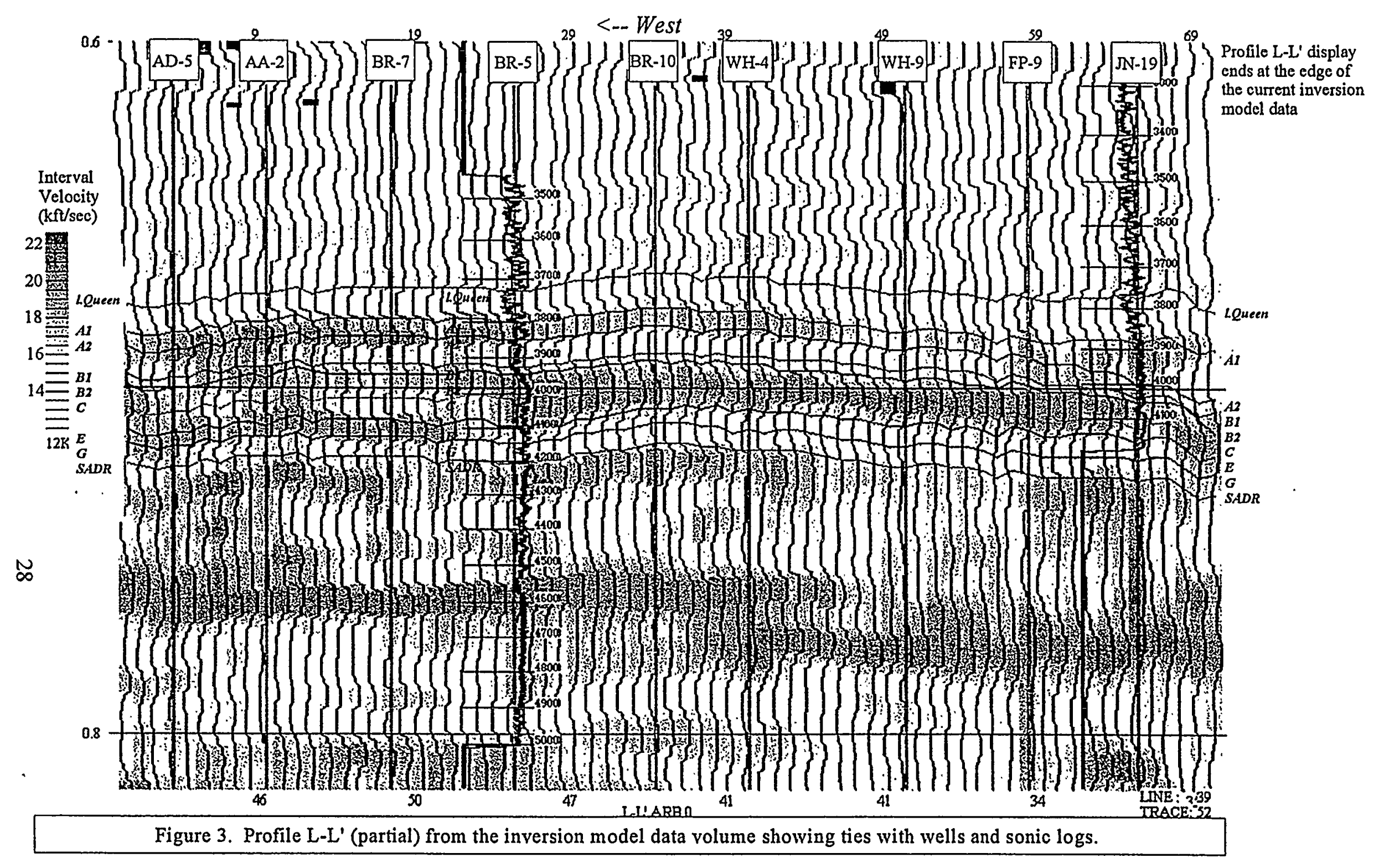




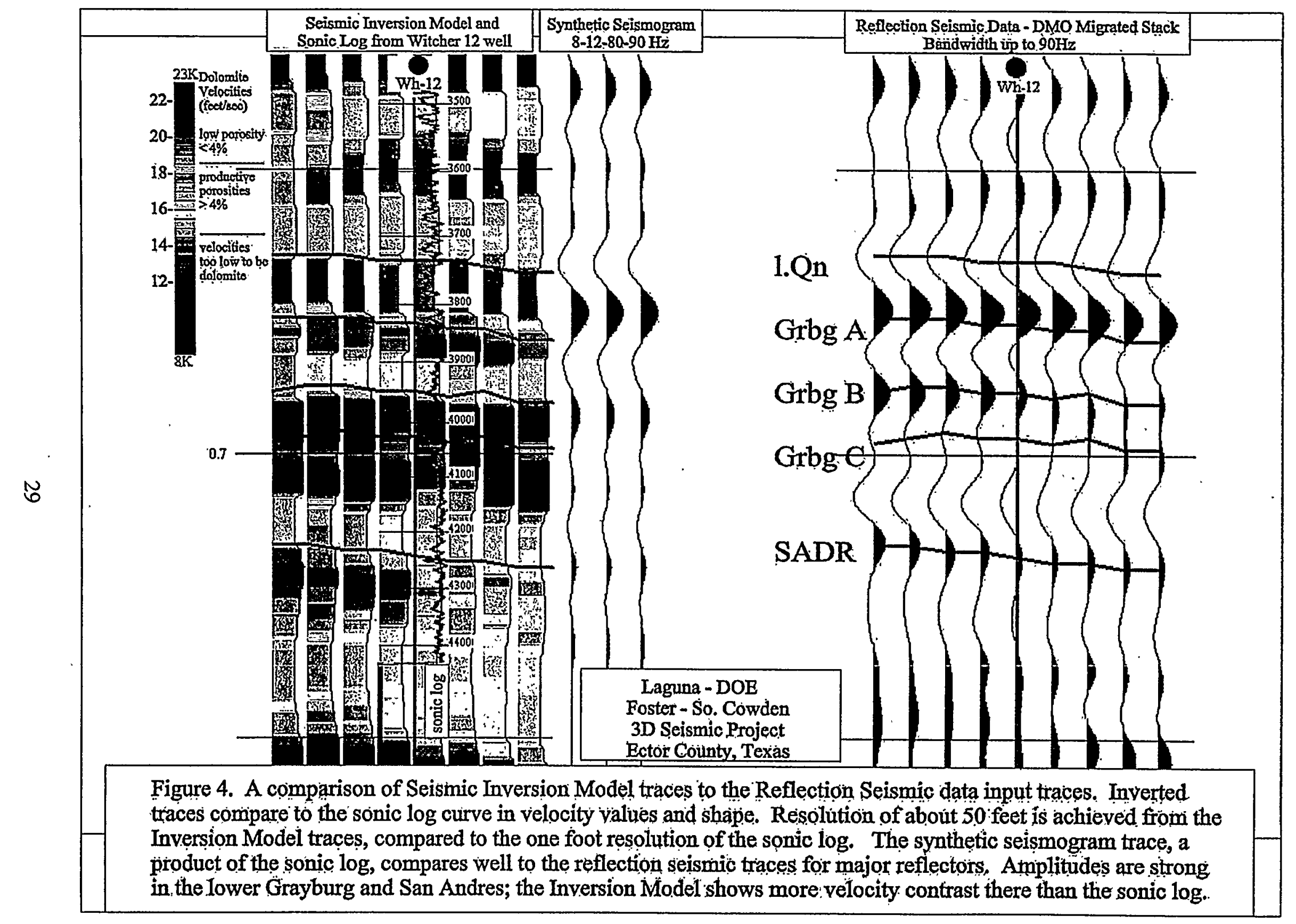




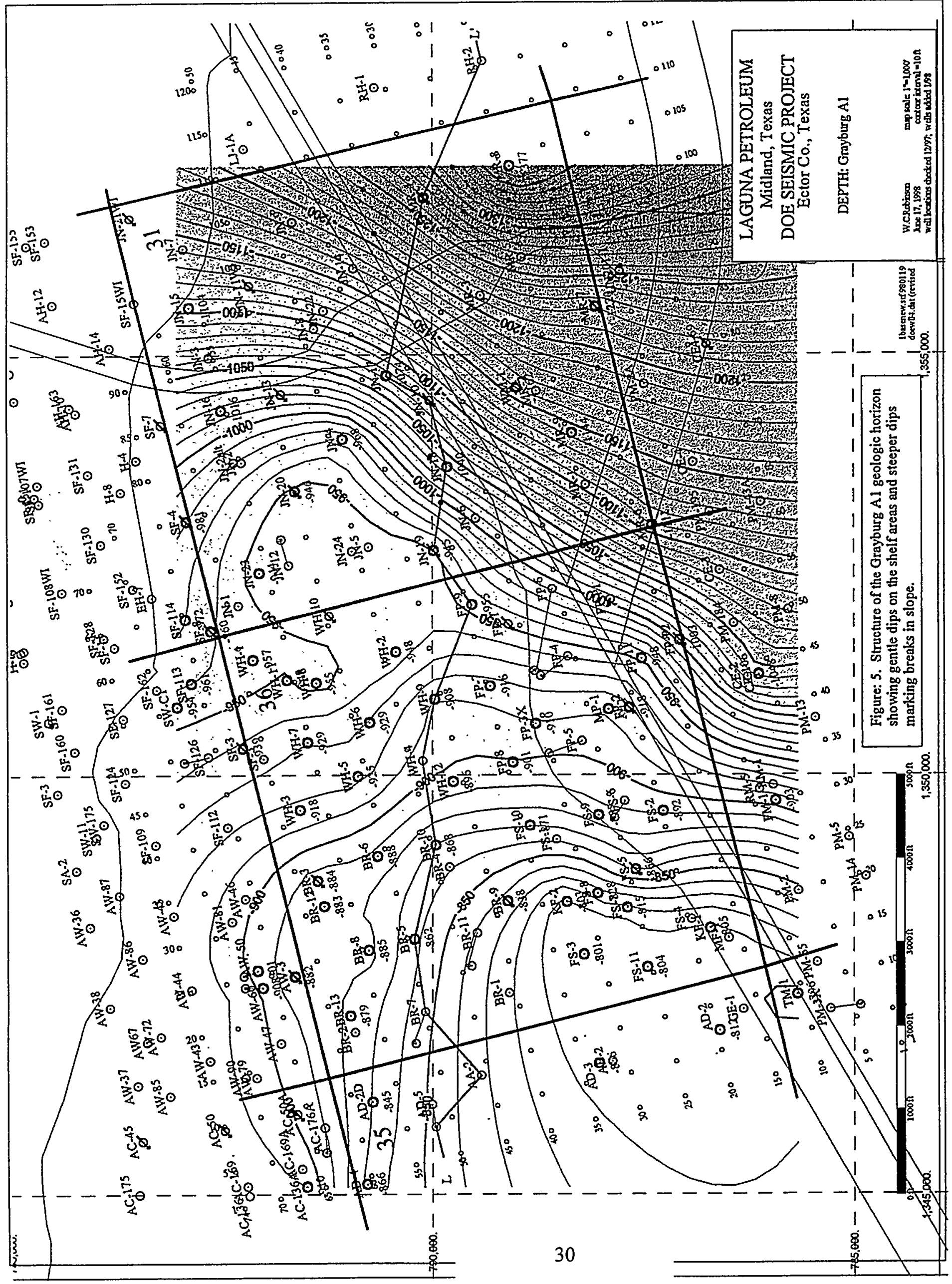




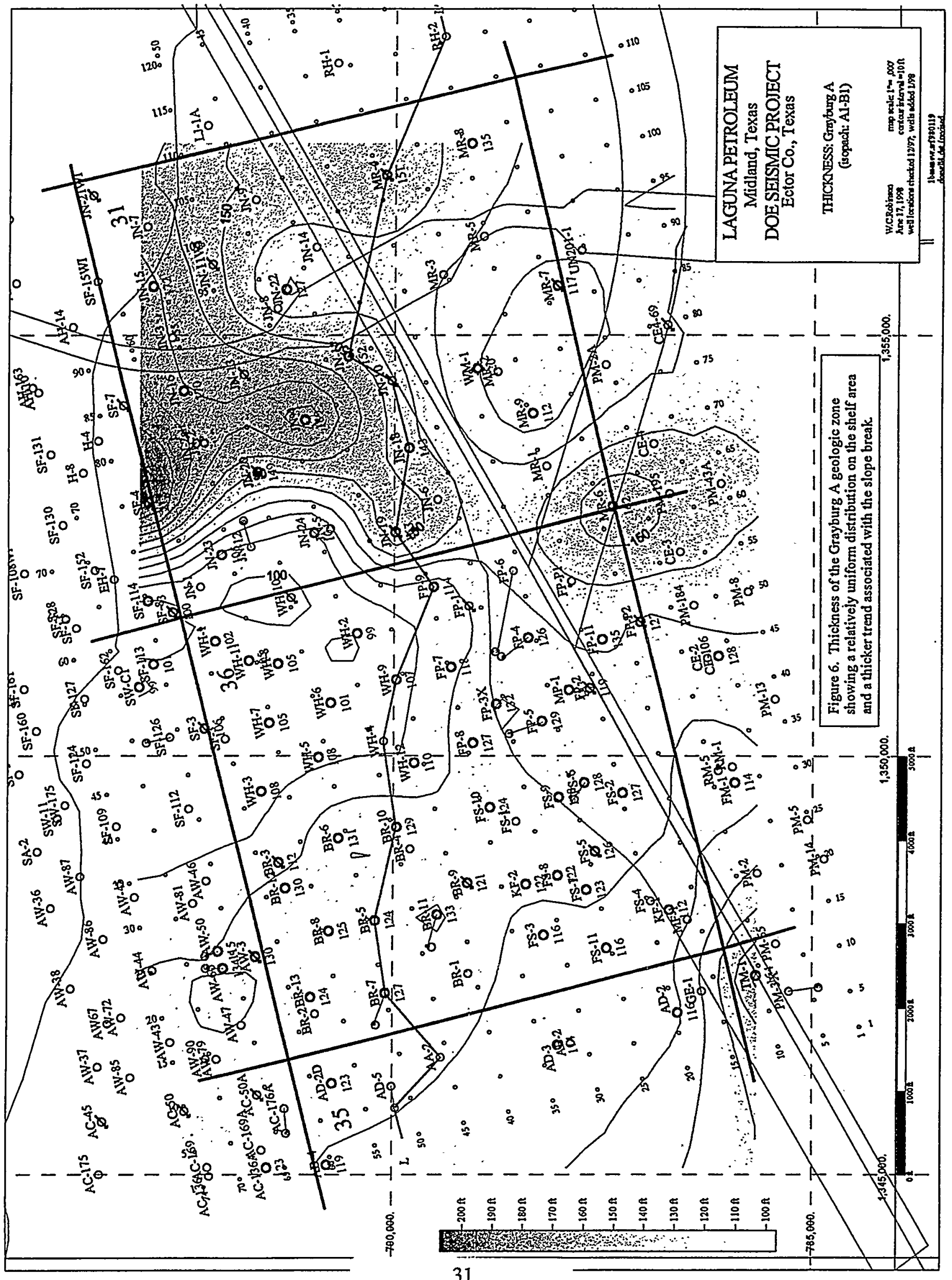



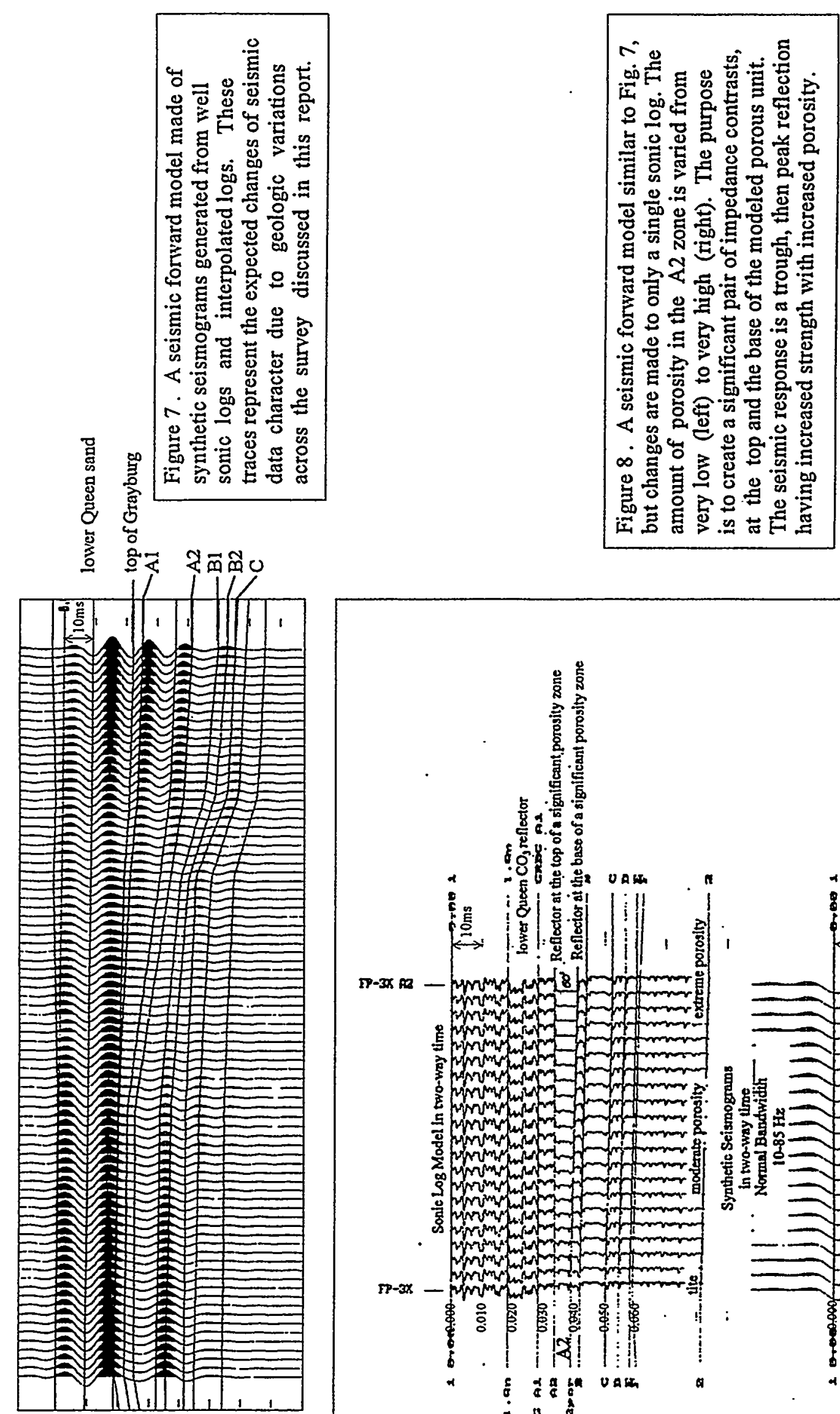

옹 응 영 영 웅 영 용

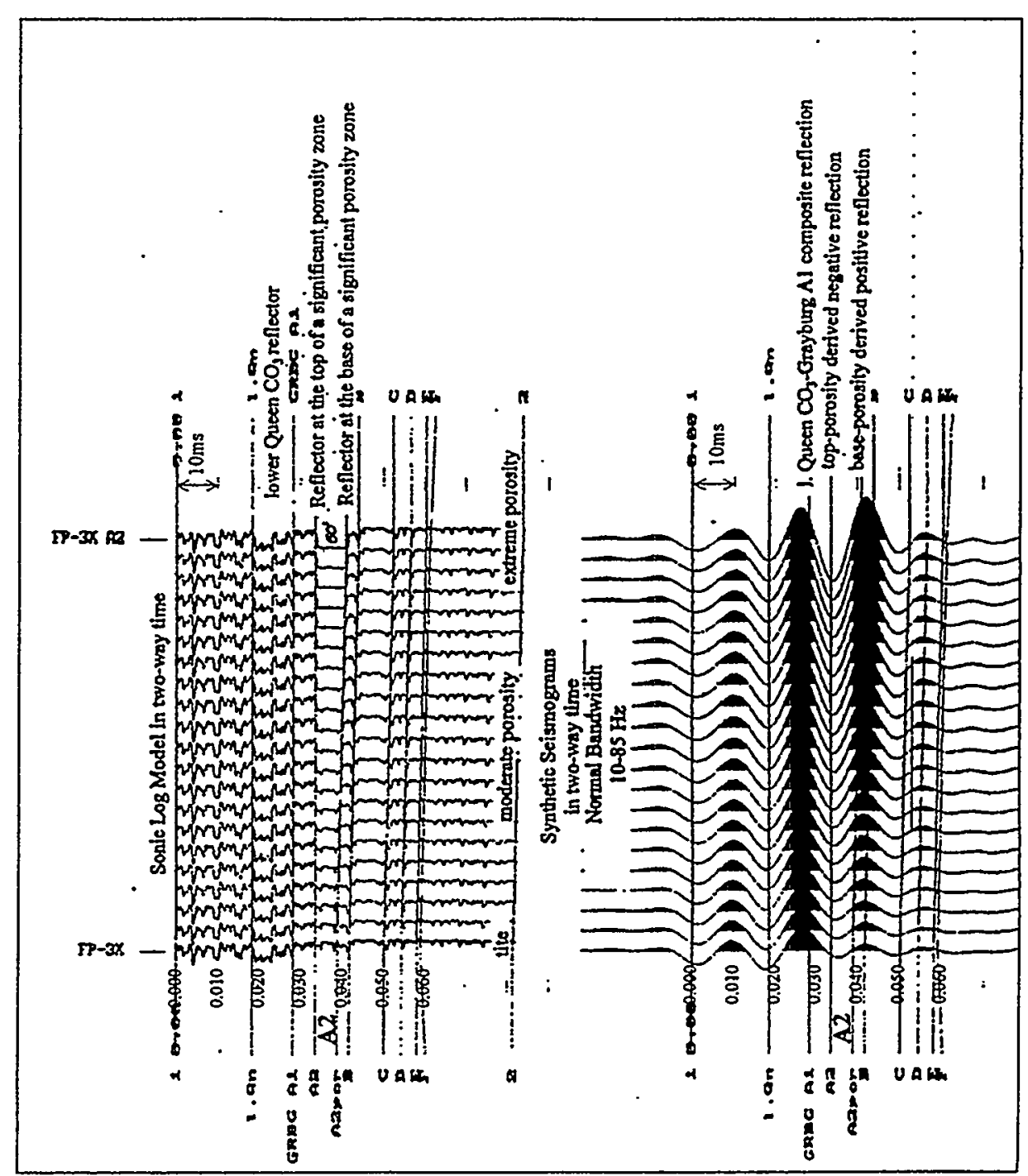




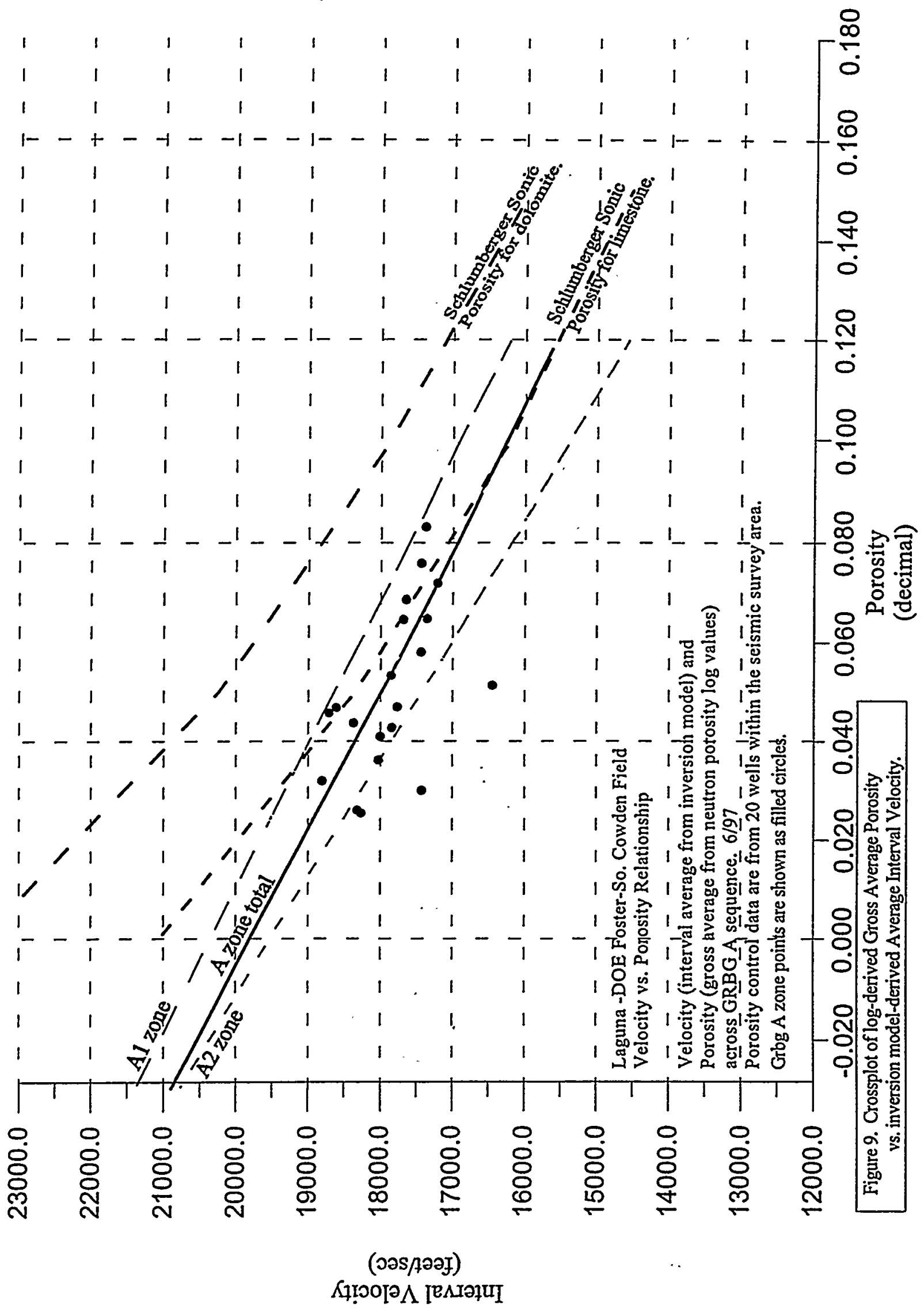




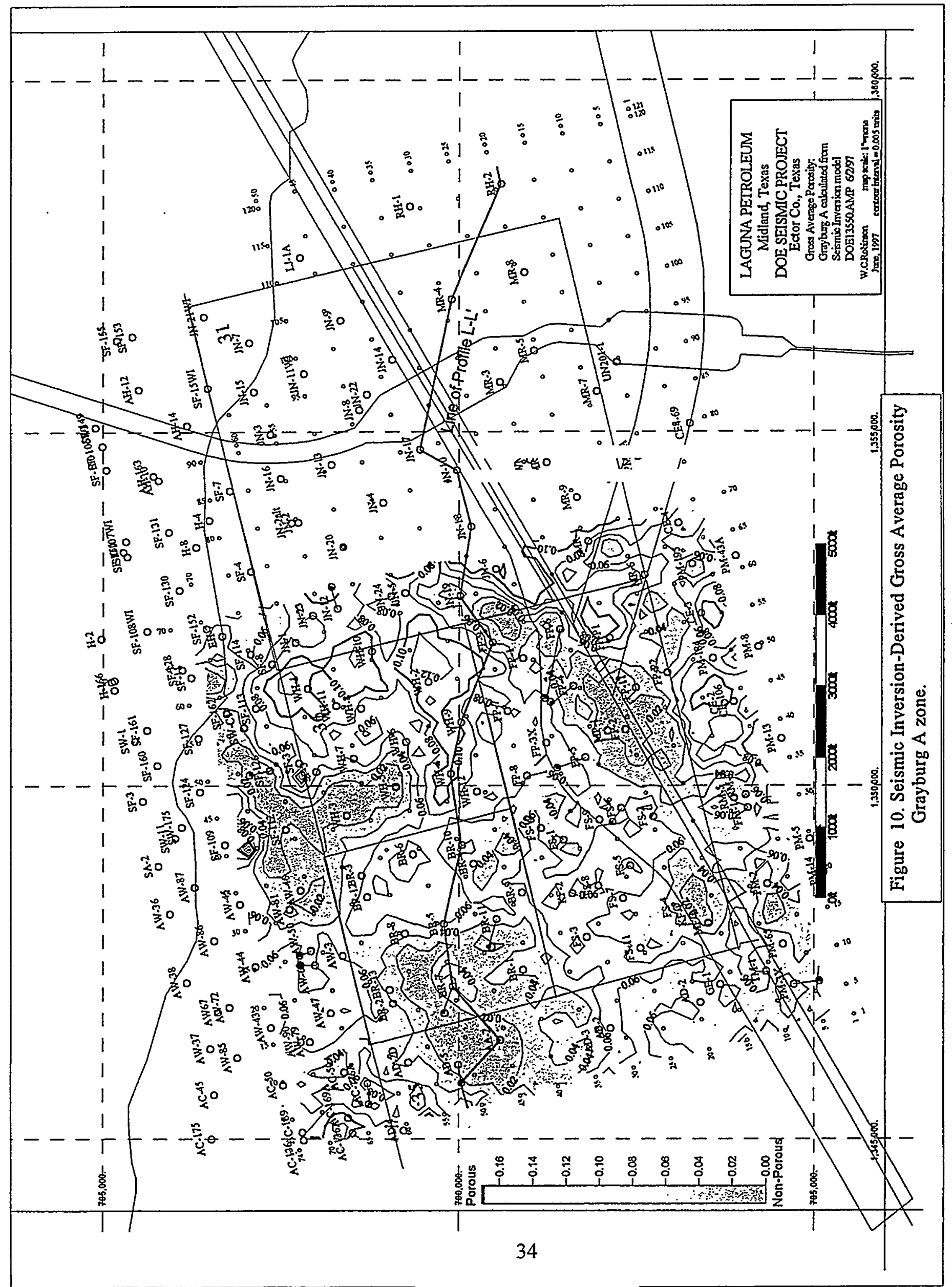




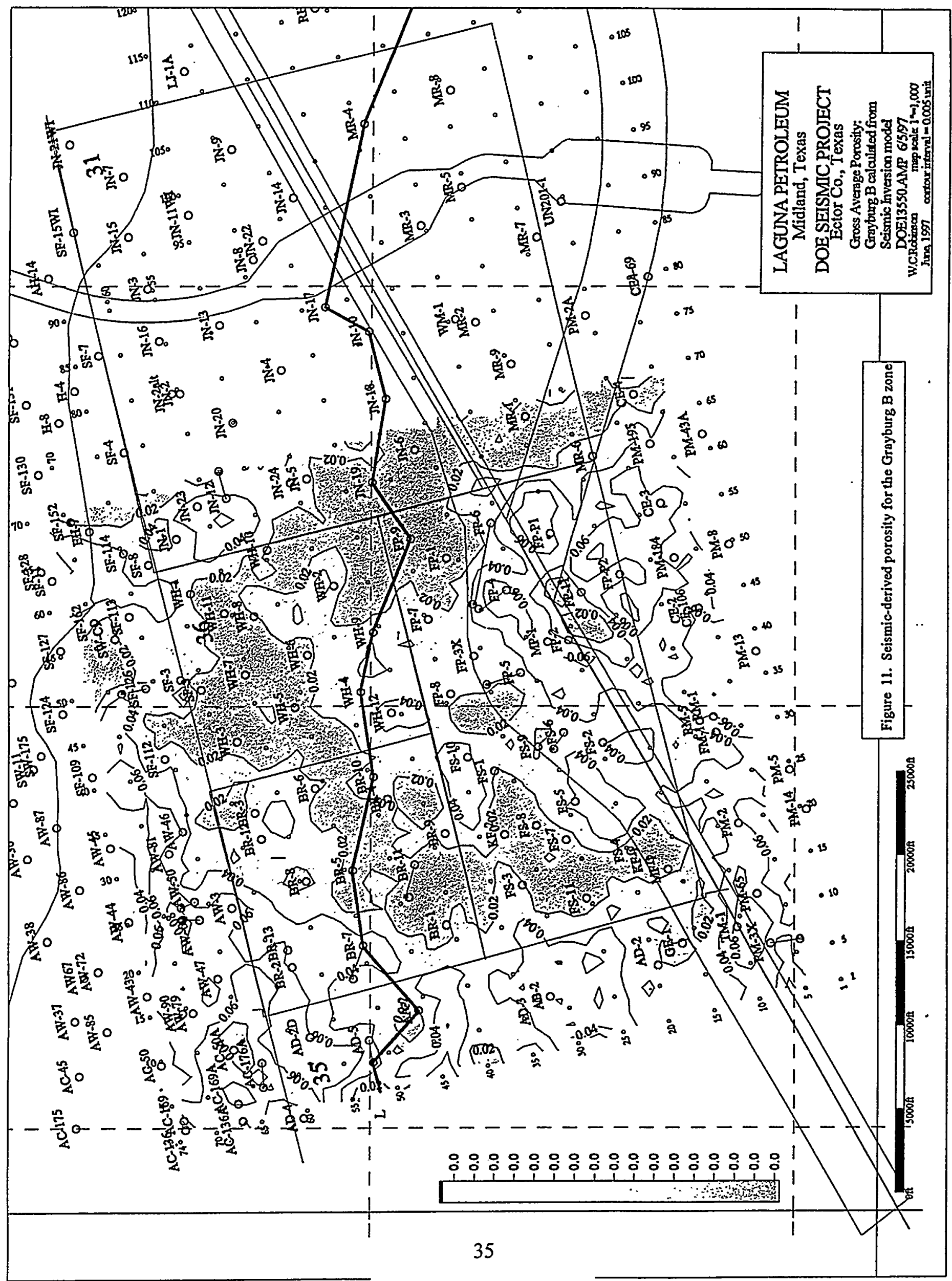




\begin{tabular}{|c|c|c|c|c|c|c|c|}
\hline & $\mathrm{HCO} 3$ & SO4 & $\mathrm{CL}$ & $\mathrm{CA}$ & MG & NA & TDS(CALC) \\
\hline UPPER GRAYBURG & 170 & 2990 & 13500 & 1530 & 450 & 7750 & 26390 \\
\hline LOWER GRAYBURG & 386 & 2632 & 20295 & 1889 & 664 & 11245 & 37332 \\
\hline SAN ANDRES & 980 & 3881 & 33846 & 2507 & 762 & 19855 & 61831 \\
\hline EARLY(1962) INJECTION WATER & 180 & 370 & 180 & 130 & 40 & 140 & 1050 \\
\hline OGALALLA(1966 INJECTION) & 260 & 1757 & 7987 & 1458 & 879 & 3020 & 10743 \\
\hline $\begin{array}{l}\text { HENDRICKS REEF WATER } \\
\text { (1971 INJECTION WATER) }\end{array}$ & 488 & 2450 & 4261 & 814 & 356 & 2510 & 10879 \\
\hline PRESENT INJECTION WATER & 793 & 3100 & 32000 & 2646 & 947 & 17757 & 57244 \\
\hline CANYON WATER & 329 & 1104 & 76532 & 5880 & 692 & 42193 & 126693 \\
\hline ELLENBURGER WATER & 439 & 1459 & 63917 & 3840 & 972 & 36064 & 106691 \\
\hline
\end{tabular}

Figure 12. "Virgin" formation and injection waters in the study area. Values are from historic water analyses data set. 


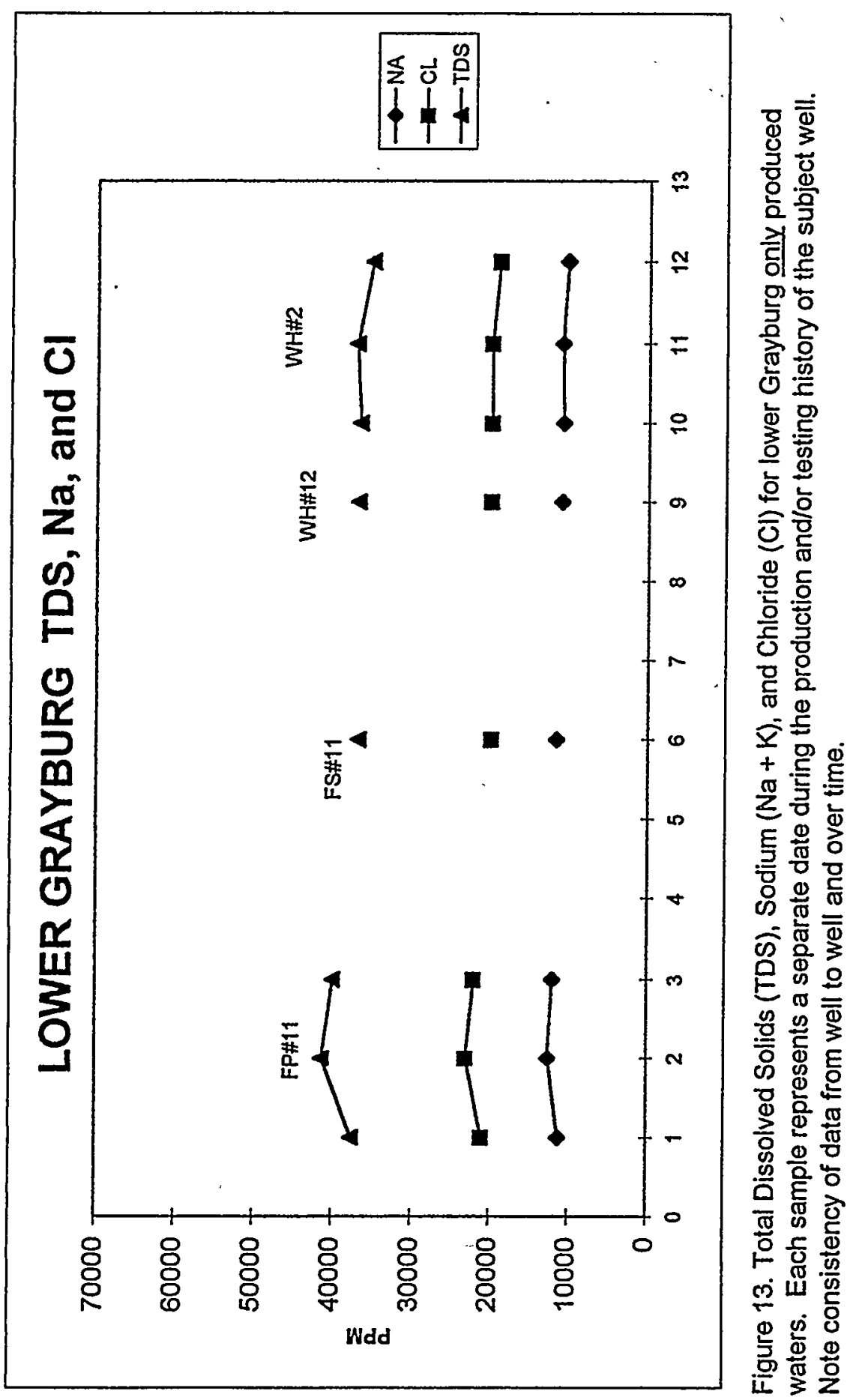




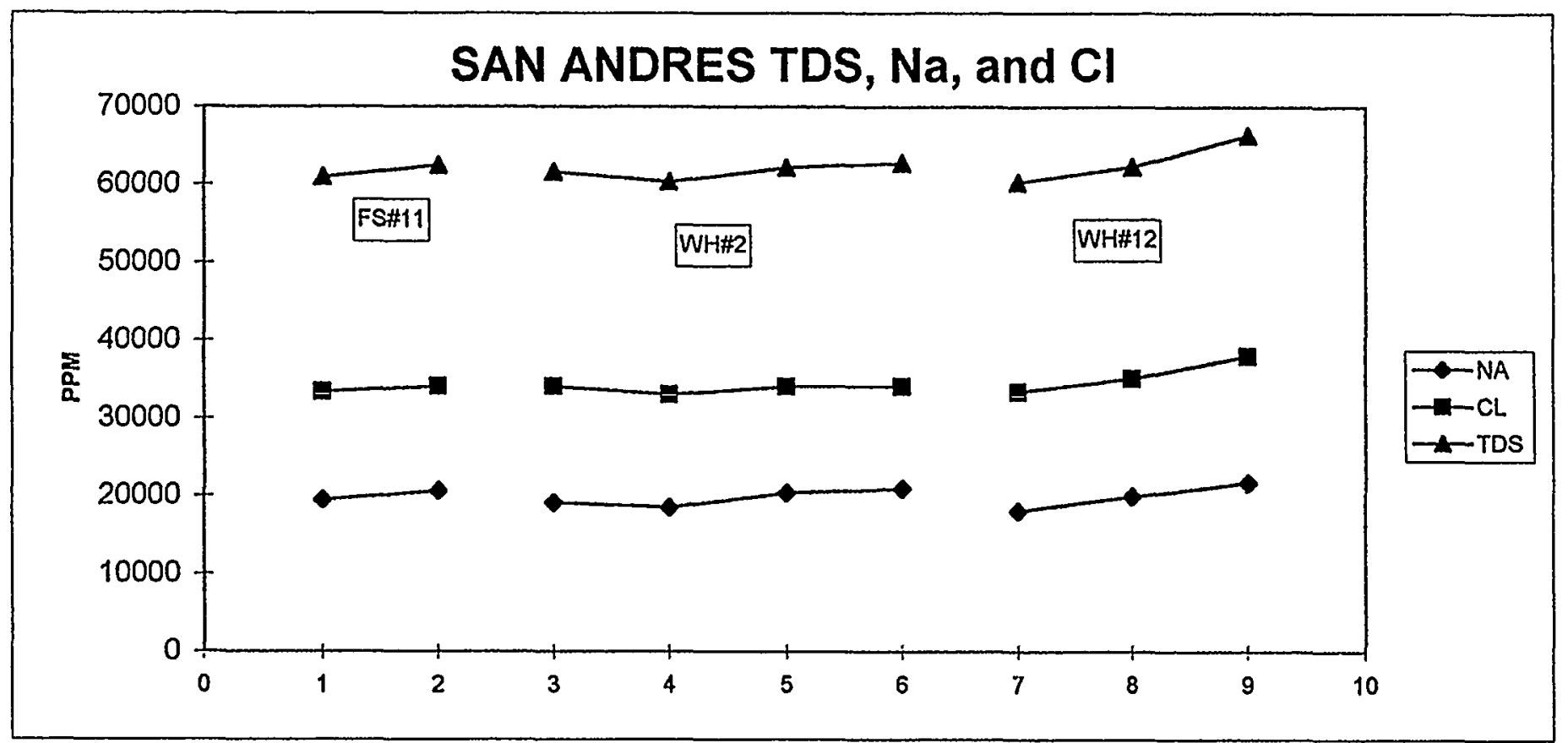

Figure 14. Total Dissolved Solids (TDS), Sodium $(\mathrm{Na}+\mathrm{K})$, and Chloride (Cl) for San Andres only produced waters. Each sample represents a separate date during the production and/or testing history of the subject well. Note consistency of data from well to well and over time. 


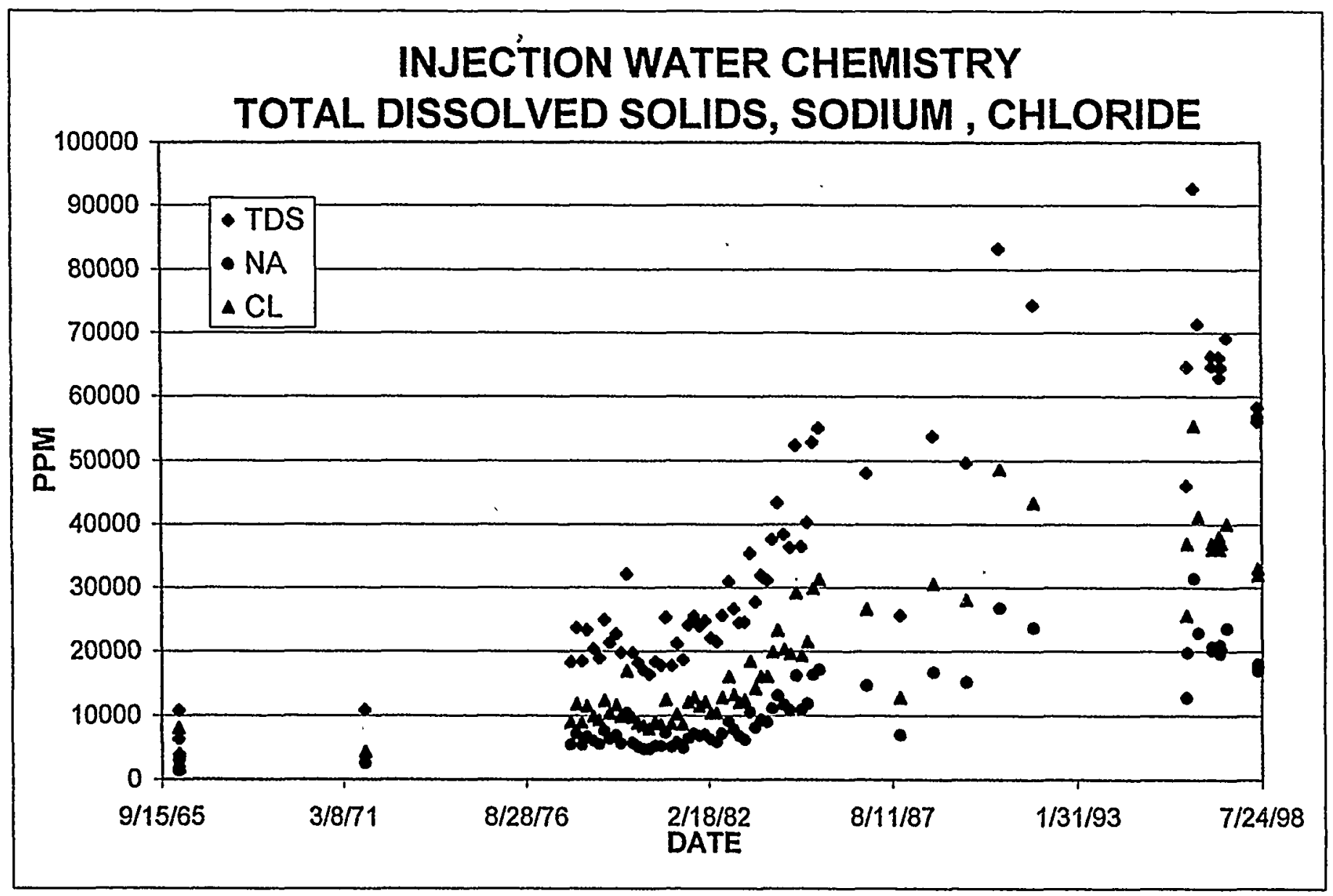

Figure 15. Total Dissolved Solids (TDS), Sodium ( $\mathrm{Na}+\mathrm{K}$ ), and Chloride (CI) in injection water, collected beginning in 1962 and continuing to the present. Note the gradual increase in the dissolved solids as different make up waters (Canyon and Ellenburger) with high TDS's are added to the system. Also note the drop in TDS, $\mathrm{Na}$, and $\mathrm{Cl}$ during the past two years as the potentially harmful makeup waters have been eliminated from the system in 1996. 


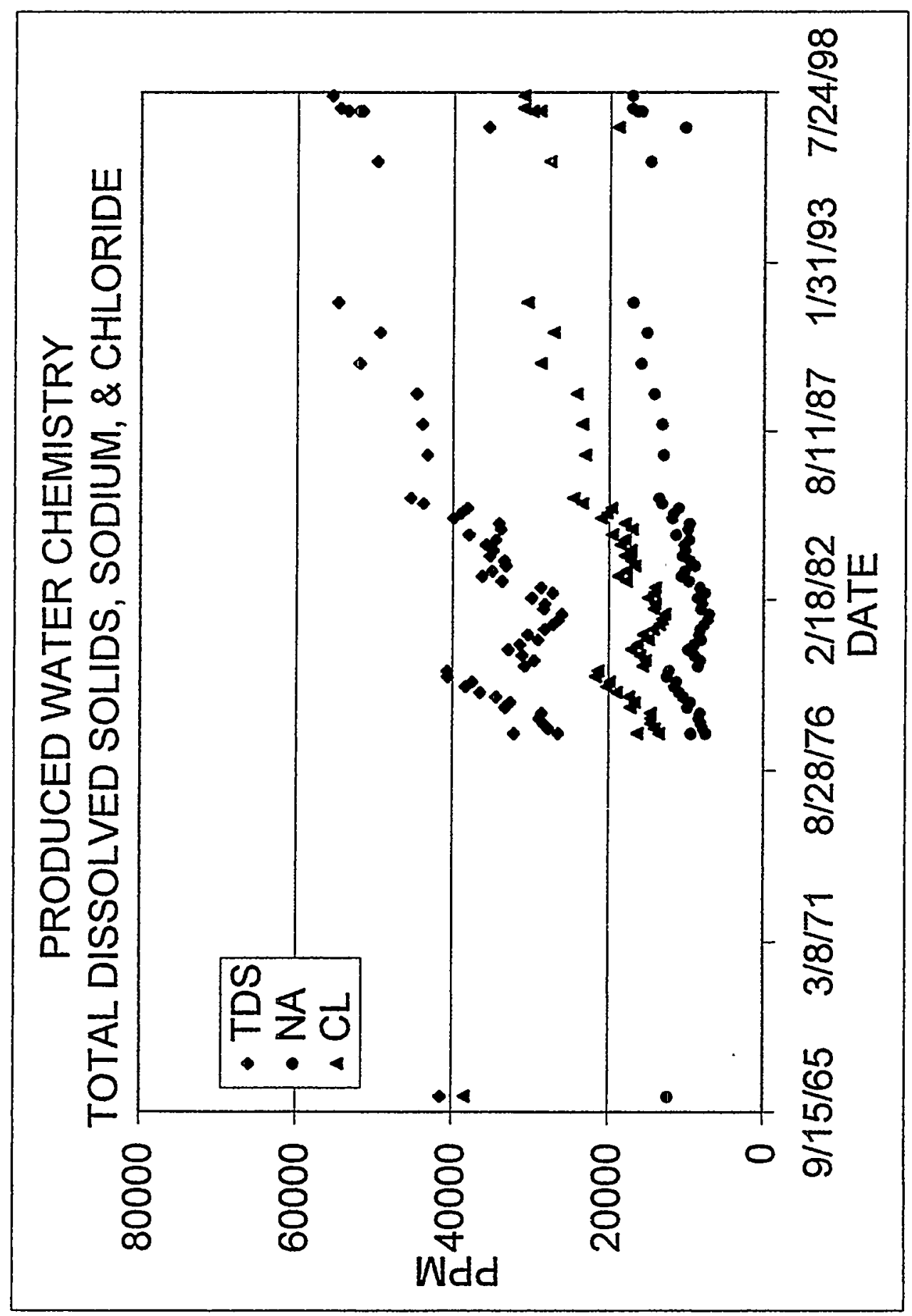

苍

可㟉

형응

市

记㝵

可 웡

월

잉

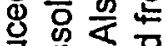

공ㅁㅇㅛ

음 통

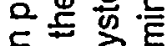

드 के

जิ

웡요

응 잉

홍 흥

○ ฐ

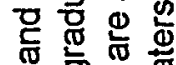

ธ。 वे के $+\ldots$ w 之은 동 톡

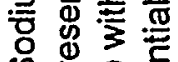

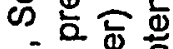
कิ 口 우은 음 믈 흘

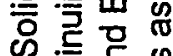
万 帘产 Ð

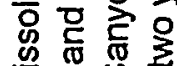

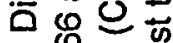
西旦 도 월 웅 ఏ。 可产竞 


\begin{tabular}{llllllllll|}
\hline & & HCO3 & CA & $M G$ & NA & SO4 & CL & TDS \\
& & & & & & & & \\
BROCK\#5 & $5 / 20 / 98$ & 841 & 3047 & 583 & 15591 & 3512 & 28000 & 51576 \\
BROCK \#5 & $8 / 24 / 98$ & 671 & 2646 & 777 & 12282 & 3300 & 23000 & 42677 \\
BROCK\#5 & $8 / 31 / 98$ & 658 & 2686 & 753 & 12925 & 3300 & 24000 & 44324 \\
BROCK\#5 & $9 / 21 / 98$ & 756 & 2566 & 826 & 13614 & 3300 & 25000 & 46063 \\
\hline
\end{tabular}

Figure 17. Chemistry of water samples from Brock $\# 5$ collected before $(8 / 11 / 98)$, and after $(8 / 24,8 / 31$, and $9 / 21$ ) a fracture stimulation. The changes in water chemistry from before to after the frac indicate a change in the produced water. The changes in water chemistry after the frac job indicate a slow increase in the precent of flood water in the produced water during the month following the frac. 


\begin{tabular}{|ccccccccccc|}
\hline & & HCO3 & CA & MG & NA & SO4 & CL & TDS & HARDNES & pH \\
BROCK\#6 & $5 / 21 / 96$ & 915 & 2720 & 656 & 14165 & 2431 & 26270 & 47194 & 9500 & 7.3 \\
BROCK\#6 & $6 / 9 / 97$ & 585 & 2085 & 680 & 10287 & 2900 & 19000 & 35538 & 8000 & 7.2 \\
BROCK\#6 & $12 / 15 / 97$ & 658 & 1684 & 923 & 11647 & 2950 & 21000 & 38864 & 8000 & 7.8 \\
BROCK\#6 & $5 / 7 / 98$ & 646 & 2245 & 972 & 13124 & 3512 & 24000 & 44501 & 9600 & 7.7 \\
BROCK\#6 & $6 / 1 / 98$ & 585 & 2165 & 728 & 13496 & 3150 & 24000 & 44099 & 8400 & 8.2 \\
BROCK\#6 & $6 / 8 / 98$ & 585 & 2085 & 874 & 10119 & 3300 & 19000 & 35965 & 8800 & 7.6 \\
BROCK\#6 & $6 / 9 / 98$ & 573 & 2125 & 753 & 10663 & 2717 & 20000 & 36832 & 8400 & 7.5 \\
BROCK\#6 & $6 / 12 / 98$ & 597 & 2165 & 680 & 11587 & 3087 & 21000 & 39118 & 8200 & 7.8 \\
BROCK\#6 & $6 / 18 / 98$ & 500 & 2125 & 704 & 10902 & 3087 & 20000 & 37320 & 8200 & 7.6 \\
BROCK\#6 & $6 / 24 / 98$ & 800 & 2300 & 365 & 13560 & 3550 & 23000 & 43600 & 7250 & 7.6 \\
"LOST WATER" & & 838 & 2445 & 1532 & 14882 & 4362 & 31000 & 55059 & & \\
\hline
\end{tabular}

Figure 18. Chemistry of water samples from Brock \#6 collected before CIBP $(5 / 21 / 96)$, after CIBP $(6 / 9 / 97,12 / 15 / 97)$ and after fracture stimulation $(5 / 7 / 98$ and6/1/98). Significant changes in water chemistry from before the production drop $(5 / 7$ and $6 / 1)$ to after the production $\operatorname{drop}(6 / 8,6 / 9,6 / 12$, and $6 / 18)$ indicate a change in the produced water. The sample from 6/24 followed the second and larger scale treatment. The "LOST WATER" water chemistry is calculated data derived from assuming the lost water represented $1 / 3$ of the total water from before the production drop. 


\begin{tabular}{|lccc|}
\hline & SODIUM & CHLORIDE & TDS \\
BEFORE PB & 20500 & 37000 & 64800 \\
AFTER PB & 20900 & 38000 & 66300 \\
\hline
\end{tabular}

Figure 19.Water chemistry from before to after an unsuccessful attempt to plug back from the

lower/Grayburg/San Andres in Foster-Pegues \#7. 


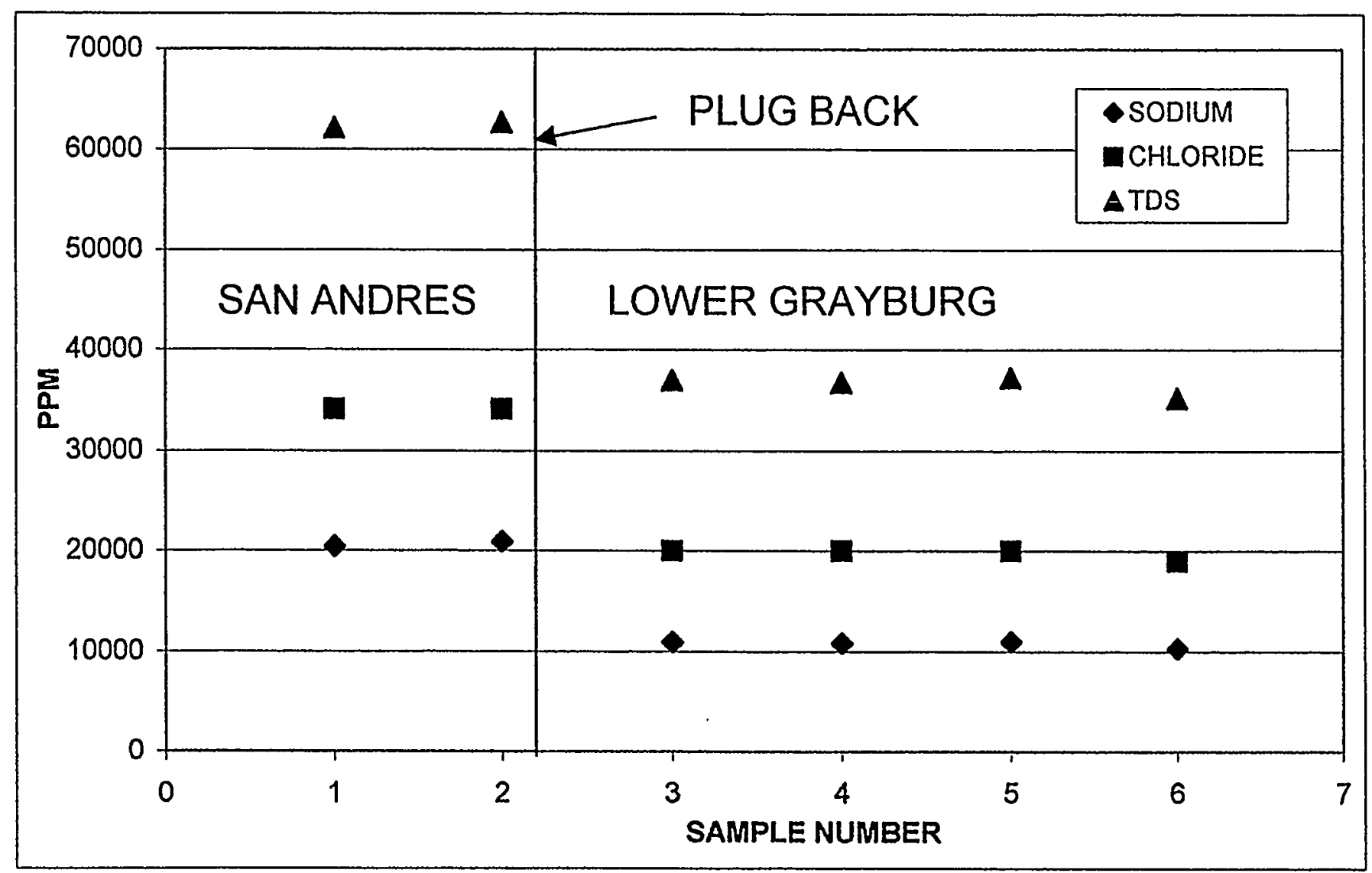

Figure 20. Example of successful "Pipeline Frac" in Witcher \#2. The formation waters from the original completion in the San Andres contained 62,500 PPM Total Dissolved Solids (TDS). The lower Grayburg formation water contains only 37,000 PPM TDS. The Pipeline Frac was therefore successful in staying in zone, and producing only lower Grayburg fluids. 


\begin{tabular}{|lcccc|}
\hline & & SODIUM & CHLORIDE & TDS \\
\hline BEFORE STIMULATION & $2 / 3 / 97$ & 18050 & 33370 & 60292 \\
AFTER STIMULATION & $2 / 7 / 97$ & 14362 & 26980 & 48900 \\
AFTER STIMULATION & $5 / 6 / 97$ & 19964 & 35145 & 62277 \\
AFTER STIMULATION & $5 / 6 / 97$ & 20955 & 37000 & 64999 \\
AFTER STIMULATION & $7 / 20 / 97$ & 21678 & 38000 & 66311 \\
AFTER STIMULATION & $8 / 14 / 97$ & 19828 & 35000 & 61571 \\
AFTER STIMULATION & $10 / 17 / 97$ & 20951 & 37000 & 64673 \\
\hline
\end{tabular}

Figure 21. Example of successful Multi-zone stimulation in Witcher \# 12. The formation waters from the original completion in the San Andres contained 60,500 PPM Total Dissolved Solids (TDS). The lower Grayburg formation water contains only 37,000 PPM TDS. The multi-zone frac was therefore successful in comingling the zones. The lower Grayburg water production eventually ceased as the produced water approached the composition of San Andres water. 


\begin{tabular}{|crrrr|}
\hline & & SODIUM & CHLORIDE & \multicolumn{1}{c|}{ TDS } \\
BEFORE CONING & $8 / 21 / 96$ & 11151 & 20951 & 37580 \\
CONING BEGINS & $2 / 7 / 97$ & 12507 & 23000 & 41361 \\
& $4 / 2 / 97$ & 15919 & 28000 & 50347 \\
SIGNIFICANT CONING & $1 / 19 / 99$ & 16784 & 31000 & 55382 \\
SIGNIFICANT CONING & $1 / 25 / 99$ & 16685 & 31000 & 55204 \\
\hline
\end{tabular}

Figure 22. Example of suspected coning in the Foster-Pegues \#11. A water sample taken soon after the lower Grayburg completion contained 39,900 PPM Total Dissolved Solids (TDS). By January 1999, the produced water had a definite "Mix" signature. 


\begin{tabular}{|lrrrrrrrr|}
\hline & HCO3 & CA & \multicolumn{2}{c}{ MG } & NA & SO4 & CL & TDS \\
BROCK\#2 & $12 / 15 / 97$ & 915 & 1483 & 1652 & 16515 & 3050 & 30000 & 53616 \\
BROCK\#3W & $6 / 9198$ & 780 & 2686 & 899 & 17483 & 2445 & 32000 & 56294 \\
BROCK\#5 & $12 / 15 / 97$ & 841 & 1523 & 1312 & 16301 & 2800 & 29000 & 51779 \\
BROCK\#6 & $12 / 15 / 97$ & 658 & 1684 & 923 & 11647 & 2950 & 21000 & 38864 \\
BROCK\#7 & $12 / 15 / 97$ & 536 & 962 & 2308 & 17021 & 2975 & 32000 & 55804 \\
BROCK\#8 & $12 / 15 / 97$ & 915 & 1924 & 1263 & 17351 & 3000 & 31000 & 55455 \\
BROCK\#10 & $12 / 15 / 97$ & 1256 & 1724 & 1069 & 16532 & 2500 & 29000 & 52082 \\
BROCK\#12 & $12 / 15 / 97$ & 829 & 1684 & 1555 & 18390 & 3075 & 33000 & 58534 \\
BROCK\#13 & $12 / 15 / 97$ & 805 & 2446 & 947 & 16009 & 3025 & 29000 & 52233 \\
\hline
\end{tabular}

Figure 23. The water chemistry of the Brock lease producing wells samples during December 1997. Note the consistency of the Total Dissolved Solids (TDS) for those wells, with the TDS for the \#3 injection well. 


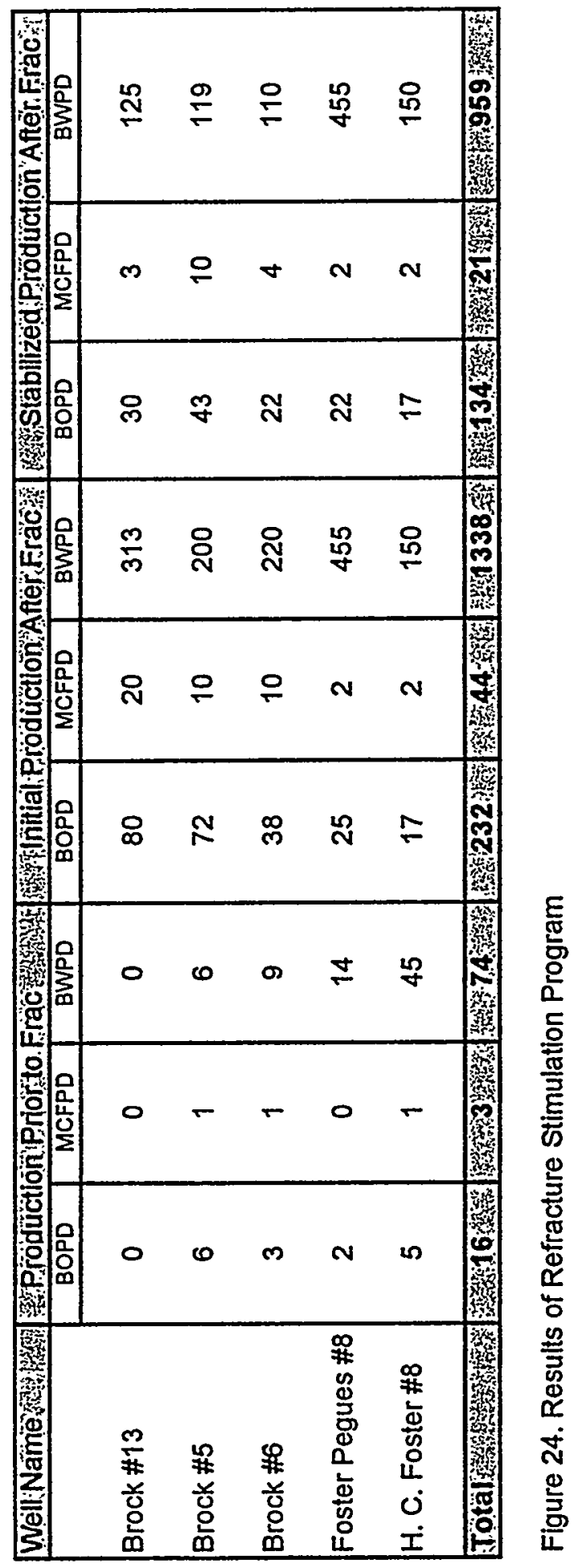




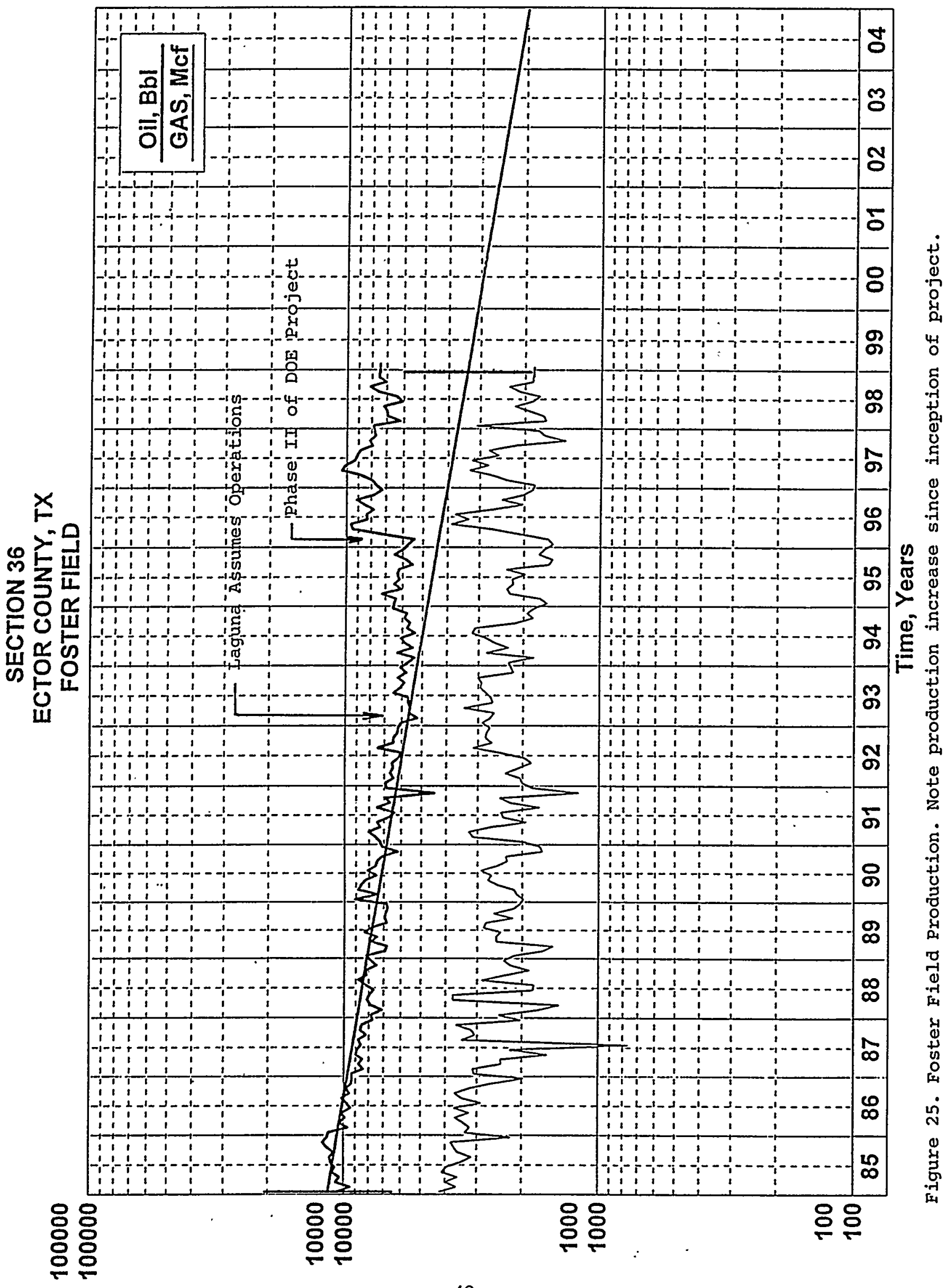

